See discussions, stats, and author profiles for this publication at: https://www.researchgate.net/publication/353778231

\title{
Research on the dissipation of green tide and its influencing factors in the Yellow Sea based on Google Earth Engine
}

Article in Marine Pollution Bulletin · November 2021

Dol: 10.1016/.j.marpolbul.2021.112801

\section{CITATIONS}

0

3 authors:

Dongxue Li

Chinese Academy of Sciences

4 PUBLICATIONS 8 CITATIONS

SEE PROFILE

Fuxiang Xu

shandong Technology and Business University

14 PUBLICATIONS 93 CITATIONS

SEE PROFILE
READS

73

Zhiqiang Gao

Chinese Academy of Sciences

92 PUBLICATIONS 568 CITATIONS

SEE PROFILE

Some of the authors of this publication are also working on these related projects:

Project The estimation of carbon sink expected benefit based on the dynamic simulation of LUCC from remote sensing and EGO model View project

Project marine ranching View project 


\title{
Research on the dissipation of green tide and its influencing factors in the Yellow Sea based on Google Earth Engine
}

\author{
Dongxue $\mathrm{Li}^{\mathrm{a}, \mathrm{b}, \mathrm{c}}$, Zhiqiang Gao ${ }^{\mathrm{a}, \mathrm{b}, *}$, Fuxiang $\mathrm{Xu}^{\mathrm{d}}$ \\ ${ }^{a}$ CAS Key Laboratory of Coastal Environmental Processes and Ecological Remediation, Yantai Institute of Coastal Zone Research, Chinese Academy of Sciences, Yantai, \\ Shandong 264003, PR China \\ b Shandong Key Laboratory of Coastal Environmental Processes, Yantai Institute of Coastal Zone Research, Chinese Academy of Sciences, Yantai, Shandong 264003, PR \\ China \\ ${ }^{\mathrm{c}}$ University of Chinese Academy of Sciences, Beijing 100049, PR China \\ ${ }^{\mathrm{d}}$ School of Public Administration, Shandong Technology and Business University, Yantai, Shandong 264005, PR China
}

\section{A R T I C L E I N F O}

\section{Keywords:}

Green tide

Dissipation

Multi-source satellite data

Long-term

Environmental factors

Influence

\begin{abstract}
A B S T R A C T
Since 2007, the outbreak of green tides has become the most serious ecological problem in the Yellow Sea. In this study, a new method was used to identify green tides in multi-source satellite data from 2007 to 2020 , and the relationship between the conditions necessary for green tide dissipation and other environmental factors was discussed. We found a "wavy" trend of green tide scales over the 14-year dissipation period. The dissipation direction was influenced by sea surface wind (SSW) and sea surface circulation (SSC). Under the action of northeast moving SSW and SSC, green tides move away from the shore and drift northward; under the action of northwest or southwest moving SSW and SSC, they moved towards the shore and drift southward. The date of dissipation was influenced by sea surface temperature (SST) and precipitation, and high SST accelerated the process of green tide dissipation, while precipitation slowed it down.
\end{abstract}

\section{Introduction}

Green tides are marine ecological disasters caused by the rapid proliferation and accumulation of large volumes of green algae under certain environmental conditions (Valiela et al., 1997), and there have been outbreaks of this in the offshore waters of many countries (Ye et al., 2011; Smetacek and Zingone, 2013; Zhou et al., 2015; Bermejo et al., 2019). The Yellow Sea green tide disaster has been an ongoing issue for 14 years, since 2007, developing into the largest green tide in the world (Liu et al., 2013; Xing et al., 2015).

The Yellow Sea Green Tide originates from the Porphyra aquaculture at the Jiangsu Shoal in the southern Yellow Sea. After the harvest of the Porphyra seaweed, large quantities of green tide algae attached to the aquaculture raft scopes are manually cleaned and reenters the sea via the tide (Fu et al., 2019). This algae continue to reproduce (Liu et al., 2015; Xiao et al., 2016), drifting northward under the influence of wind and waves (Son et al., 2015). Finally, a million tons of green tide biomass accumulated in the coastal waters of the Shandong Peninsula in late June and July (Liu et al., 2016). The resources available to artificially collect algae are limited, and as the green tide enters the dissipation phase, some of the algae from the green tide will be washed ashore by waves and tides, and affect the ecological environment and human activities in the coastal areas, Some of it will decompose naturally in the sea, releasing a large amount of nutrients and changing the ecology of the marine environment (Chimney and Pietro, 2006; Wang et al., 2012), affecting other biological groups in the water body (Wang et al., 2019), affecting other biological groups in the water body and increasing the likelihood of secondary marine disasters such as red tides (Kong et al., 2018).

Many studies have shown that environmental factors such as sea surface temperature (SST) (Kim et al., 2011; Xiao et al., 2016), precipitation, sea surface wind (SSW) and sea surface circulation (SSC) (Taylor et al., 2001) influence the scale, drifting paths, and coverage area of green tides. At present, the relationships between the developmental patterns of green tides and environmental factors have been studied (Jin et al., 2018; Zhang et al., 2020a; Zhang et al., 2020b), especially the relationship between the outbreak of green tides and environmental factors (Bao et al., 2015; Huo et al., 2016; Hu et al., 2017), However, few studies have focused on the temporal and spatial distribution characteristics of long-term green tide dissipation, especially the relationships

\footnotetext{
* Corresponding author at: Yantai Institute of Coastal Zone Research, Chinese Academy of Sciences, Yantai 264003, PR China.

E-mail address: zqgao@yic.ac.cn (Z. Gao).
} 
between the spatial and temporal characteristics of green tide dissipation and environmental factors, which will contribute to the prevention and control of green tide disaster and further grasp the mechanism of green tide dissipation.

Moderate-resolution Imaging Spectroradiometer (MODIS) images often used to monitor green tides as they cover large areas and revisit sites once each day. However, it is difficult to identify and extract green tide information, such as the beginning of the initial phase or the end of the dissipation phase, through MODIS with low spatial resolution because the area affected by green tides is relatively small during these two phases. With higher spatial resolutions, Sentinel 2 (S2), Landsat 5 (L5), and Landsat 8 (L8) can be used to identify and extract green tide information during these two phases. Approaches utilizing multi-source data can also compensate for the limitations of a single data source. However, the differences in spatial resolution between the datasets from multiple sources have a significant impact on estimations of green tide areas (Xu et al., 2016; Kim et al., 2018), which can be significantly larger than the areas identified from high spatial resolution images. (Cui et al., 2012). Currently, the main methods used to help ensure the consistency of the green tide area extracted are the mixed pixel decomposition and relational model; but they still cannot produce consistent localization of green tides from multi-source satellite data.

Based on the above analysis, this study adopted a wide range of highresolution satellite data, to ensure consistency in extracting the areas of coverage and localization of green tides from multi-source satellite data. On this basis, S2, L5, and L8 auxiliary MODIS data were used to summarize the green tide information between 2007 and 2020, analyze the temporal and spatial distribution characteristics of green tide dissipation. The relationship between the temporal and spatial distribution characteristics of green tide distribution and the main environmental factors is analyzed.

\section{Data and methods}

\subsection{Data source and data preprocessing}

All data used in this study were provided by the Google Earth Engine (GEE). The level 2A S2 MSI surface reflectance product has a spatial resolution of $10 \mathrm{~m}$ after orthorectification and atmospheric correction (https://developers.google.com/earth-engine/datasets/catalog/sentine 1-2). The atmospheric correction of the S2 dataset was achieved using the Sen2Cor processor algorithm (Main-Knorn et al., 2017). The L5 ETM and L8 OLI/TIRS surface reflectance products have a spatial resolution of $30 \mathrm{~m}$ after atmospheric correction (https://developers.google.com/ earth-engine/datasets/catalog/landsat). Atmospheric correction of the L5 and L8 datasets was achieved using the Landsat Ecosystem Disturbance Adaptive Processing System (LEDAPS) (Sayler, 2020a) and Landsat Surface Reflectance Code (LaSRC) (Sayler, 2020b), respectively. The MODIS Terra surface reflectance products have a spatial resolution of $250 \mathrm{~m}$ (https://developers.google.com/earth-engine/datasets/catalo g/MODIS_006_MOD09GQ). The MODIS atmospheric correction algorithm uses MODIS atmospheric products (MOD04, aerosols; MOD05, water vapor; MOD07, ozone; MOD35, cloud mask) and ancillary datasets (digital elevation model, atmospheric pressure) as inputs. The algorithm makes use of a lookup table, which is created using the $6 \mathrm{~S}$ code to supply the required path radiance, total transmittance, and atmospheric top reflectance for a variety of Sun-view geometries and aerosol loadings (Vermote and Vermeulen, 1999). While the atmospheric correction algorithms of the S2, L5, L8 and MODIS were developed for applications over land, they can also be applied over the water surface (Doernhoefer et al., 2016; Chen et al., 2021; Schreyers et al., 2021). And the root-mean-square error (RMSE) between Sen2Cor Bottom-OfAtmosphere (BOA) reflectance and in-situ measurements ranges from 0.002 to 0.005 (Doernhoefer et al., 2016), the RMSE between LaSRC remote sensing reflectance and near-simultaneous in-situ data ranges from 0.002 to 0.004 (Ilori et al., 2019), the RMSE between MODIS surface reflectance products and in situ data ranges from 0.002 to 0.004 (Cui et al., 2014).

Precipitation and sea surface wind (SSW) data were from the fifthgeneration European center for medium-range weather forecast atmospheric reanalysis data of the global climate (ERA5) with a horizontal spatial resolution of approximately $27,830 \mathrm{~m}$ per day (https://developer s.google.com/earth-engine/datasets/catalog/ECMWF_ERA5_DAILY).

The SSW data provided by ERA5 had the best performance for simulating the wave height of the Yellow Sea coastal areas (Wu et al., 2020). The observations from surface weather stations in China's major land areas in 2018, the error of ERA5 precipitation was $5.4 \mathrm{~mm}$ (Wang et al., 2020).

SST and SSC data were from the daily Hybrid Coordinate Ocean Model (HYCOM) data with a horizontal spatial resolution of about $8906 \mathrm{~m}$ (http s://developers.google.com/earth-engine/datasets/catalog/HYCOM_sea _temp_salinity and https://developers.google.com/earth-engine/datasets /catalog/HYCOM_sea_water_velocity). HYCOM is a data-assimilative hybrid isopycnal-sigma-pressure (generalized) coordinate ocean model, which assimilates satellite altimeter data, conductivity temperature from depth sensors (CTD), expendable bathythermographs (XBT), Argo buoy, and glider data (Cummings and Smedstad, 2013), it can describe the state of the near-surface ocean reasonably well and can be used to predict mesoscale ocean processes in the seas around China (Xu et al., 2011).

Data preprocessing was mainly completed in GEE, including cloud removal and the clipping of satellite images. Screening, clipping, and calculation of environmental factor data. In GEE, after the spatial region is uploaded, data filtering and other operations can be performed using scripts, and multi-year data can produced simultaneously, thus improving data processing efficiency.

\subsection{Green tide extraction}

In this study, we used GEE as the main satellite image processing tool for detecting green tide information. Floating green tide algae contains chlorophyll and due to its cell structure, its spectral curve exhibits an absorption valley in the red-light band (R). Its spectral curve also exhibits a reflection peak in the near-infrared band (NIR). The seawater covered by green tide algae also has the same characteristics (Ramsey et al., 2012). Based on the spectral differences between natural seawater and seawater covered by green tide algae, scholars have proposed many green tide information detection algorithms, among which the normalized difference vegetation index (NDVI) is a common method for extracting green tide information from remote sensing images, which can be expressed by Eq. (1):

$\mathrm{NDVI}=\frac{\rho_{\text {NIR }}-\rho_{\text {Red }}}{\rho_{\text {NIR }}+\rho_{\text {Red }}}$

Eq. (1) considers the NDVI of each pixel on the image, and $\rho_{\text {NIR }}$ and $\rho_{\text {Red }}$ are the reflectivities in the NIR and R, respectively. In this paper, NIR uses Sentinel2's B8, Landsat5's B4, Landsat8's B5, MODIS's sur_refl_b02, and R uses Sentinel2's B4, Landsat5's B3, Landsat8's B4, and MODIS's sur_refl_b01.

The methodology for extracting green tide information is based on a combination of a gray-level thresholding algorithm and visual interpretation. First, the NDVI threshold range is determined and the NDVI distribution map of the study area is generated and displayed in the GEE layer. Then, based on an interpretation of the visual features, the NDVI thresholds are adjusted to ensure that the extracted green tide information is as consistent with the field condition as possible. Visual interpretation is mainly based on RGB true color images and false color images. Since 2016, our project team has carried out the use of unmanned aerial vehicles to monitor green tides, we used these data to assist the visual interpretation and data verification. Moreover, the information regarding green tide, extracted through the method proposed in this paper, was verified by comparing it to data from the Green tide bulletin in North China sea issued by the North China Sea Branch of the 

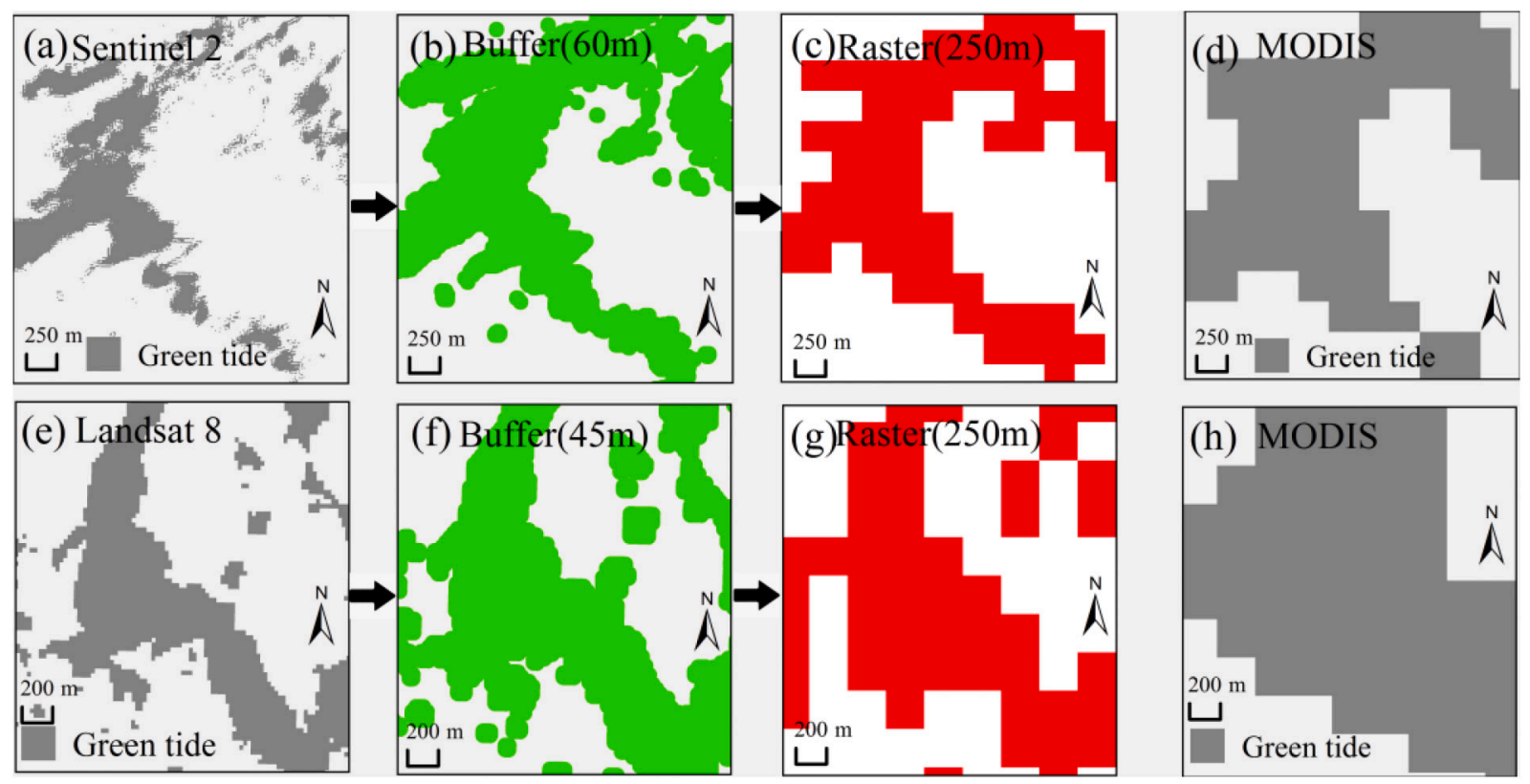

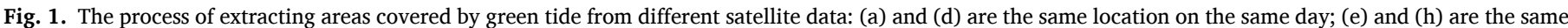

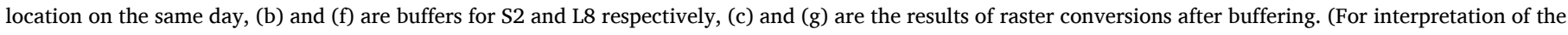
references to color in this figure legend, the reader is referred to the web version of this article.)
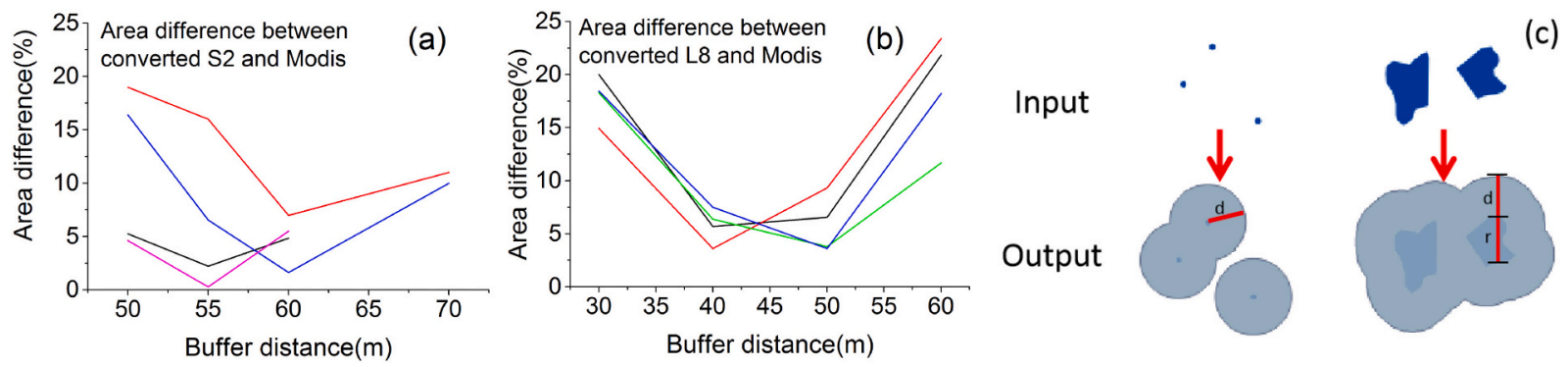

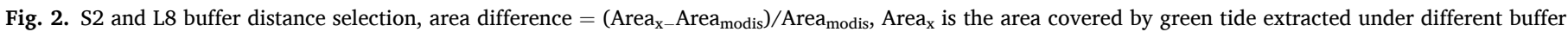
distances of S2 and L8. (c) is the buffer diagram, where " $r$ " is the length of the element and " $\mathrm{d}$ " is the buffer distance.

State Oceanic Administration (NCSBSOA) (Marine Environmental Protection Department of North China Sea Branch of State Oceanic Administration, 2021). The pearson correlation coefficient of the matching data in the same period from 2010 to 2018 was 0.78 , Sig. $<0.001$ (2-tailed), and the RMES $=81 \mathrm{~km}^{2}$. The NCSBSOA used satellites, ships, and land-shore field survey to comprehensively monitor the green tide in the Yellow Sea, and its monitoring results are closer to the distribution of green tides. The extraction difference between us and NCSBSOA is mainly in the early stage and dissipation stage of the green tide, the result extracted through our method is generally large, which is mainly affected by the satellite resolution, the extracted value of mixed pixel region with small green tide patch distribution is greater than the actual value. We must make a trade-off between the consistency and accuracy of many years of data, and finally determine the use of our method to extract the long-term series of green tides.

After extracting the green tide information, we extract the influence area of each green tide by manually drawing the outer boundary line of the green tide coverage area (see supplementary Fig. 1 for the description of the drawing method).

\subsection{Multi-source satellite data processing}

Because of differences in the spatial resolutions of satellite images from the same day, the extracted areas covered by green tide can vary.
The areas covered by green tide extracted from MODIS images with low resolutions are larger than those extracted from S2 and L5/8, with higher spatial resolutions (as shown in Fig. 1). The ratios of areas covered by green tide extracted by MODIS to those extracted by S2 and L8 are approximately $2.5-3.5$ and $1.5-2.5$, respectively.

To ensure consistency in the results of green tide extraction from multi-source data, we widened the range of high-resolution satellite data deemed to be acceptable. First, the elements extracted by the highresolution satellite were used to create a buffer (Figs. 1b, f, and 2c). They were then converted to rasters with $250 \mathrm{~m}$ spatial resolution (Fig. 1c and g).

The selection of the buffer distance is key to data conversion. The larger the difference in resolution, the larger the appropriate buffer size. A number of MODIS and S2, and MODIS and L8 paired samples with the same dates were selected. Buffer zones with different distances were established for S2 and L8, and the areas of coverages extracted from different buffer distances was compared with the MODIS areas of coverage, and the difference in areas were maintained below $10 \%$ (Fig. 2a and b). In this study, we transformed the area and location of the green tide data from S2, L5, and L8 images into formats consistent with MODIS images; the buffer distance for S2 data was set to $60 \mathrm{~m}$, and the buffer distances for the L5 and L8 data were set to $45 \mathrm{~m}$. Using buffers, the information for a single pixel in the high-resolution image was converted from $10 \times 10 \mathrm{~m}$ (S2) or $30 \times 30 \mathrm{~m}$ (L8) to a data point with a 

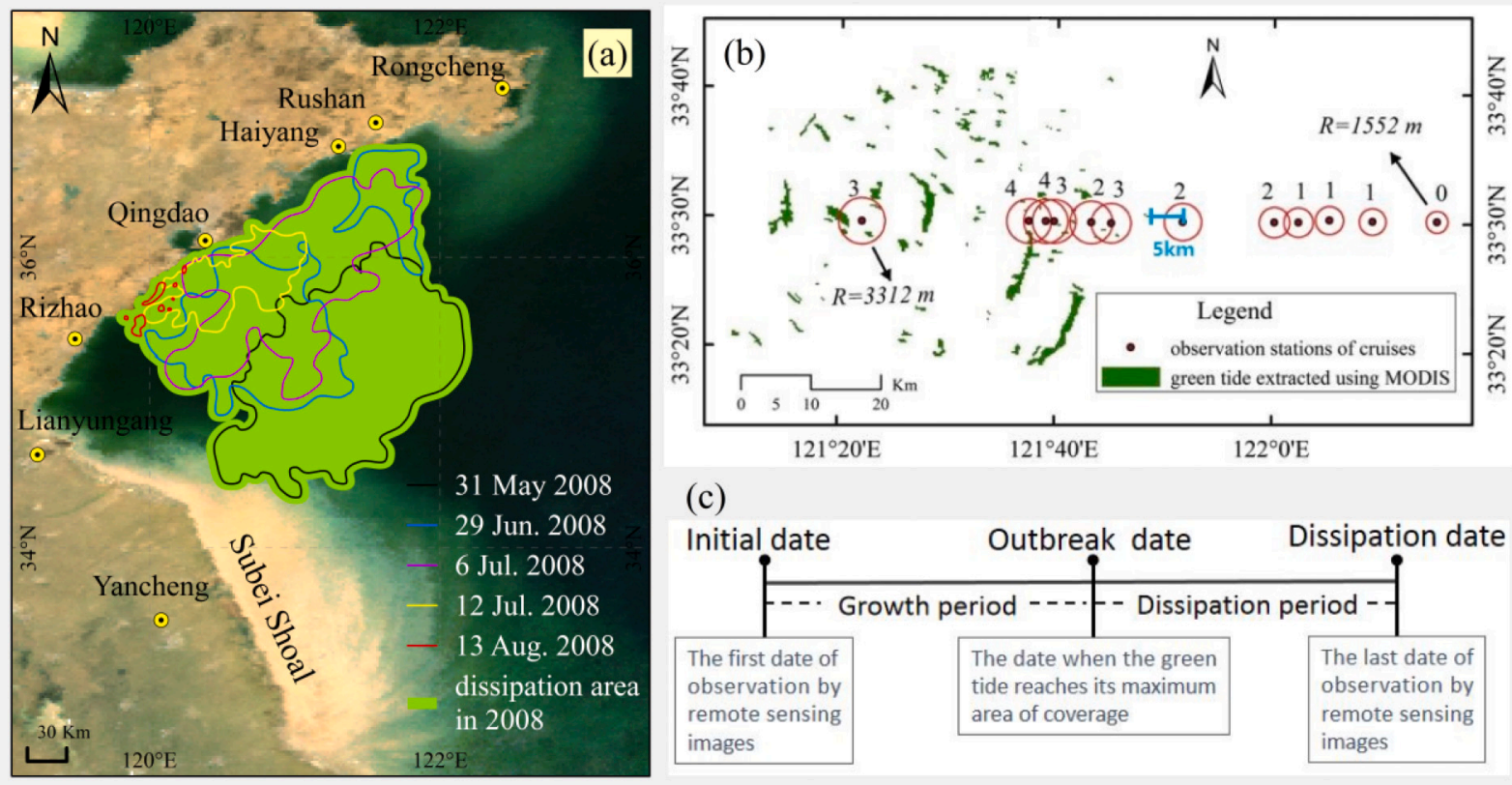

(c)

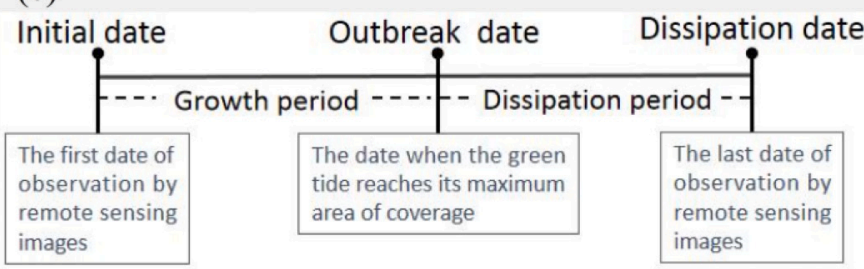

Fig. 3. (a) Schematic diagram of the methodology for determining dissipation area (in green). The solid lines of different colors are the boundaries around areas covered by green tide on different dates; colors define chronology, in the following order: black, blue, purple, yellow, and red. Panel (b) Superimposition of green tide at the observation points on 19th May 2016 (Xu et al., 2017), numbers above the dots represent the magnitude levels of green tide patches at the field observation sites (see supplementary Table 1). Panel (c) is the division of green tide stage. (For interpretation of the references to color in this figure legend, the reader is referred to the web version of this article.)

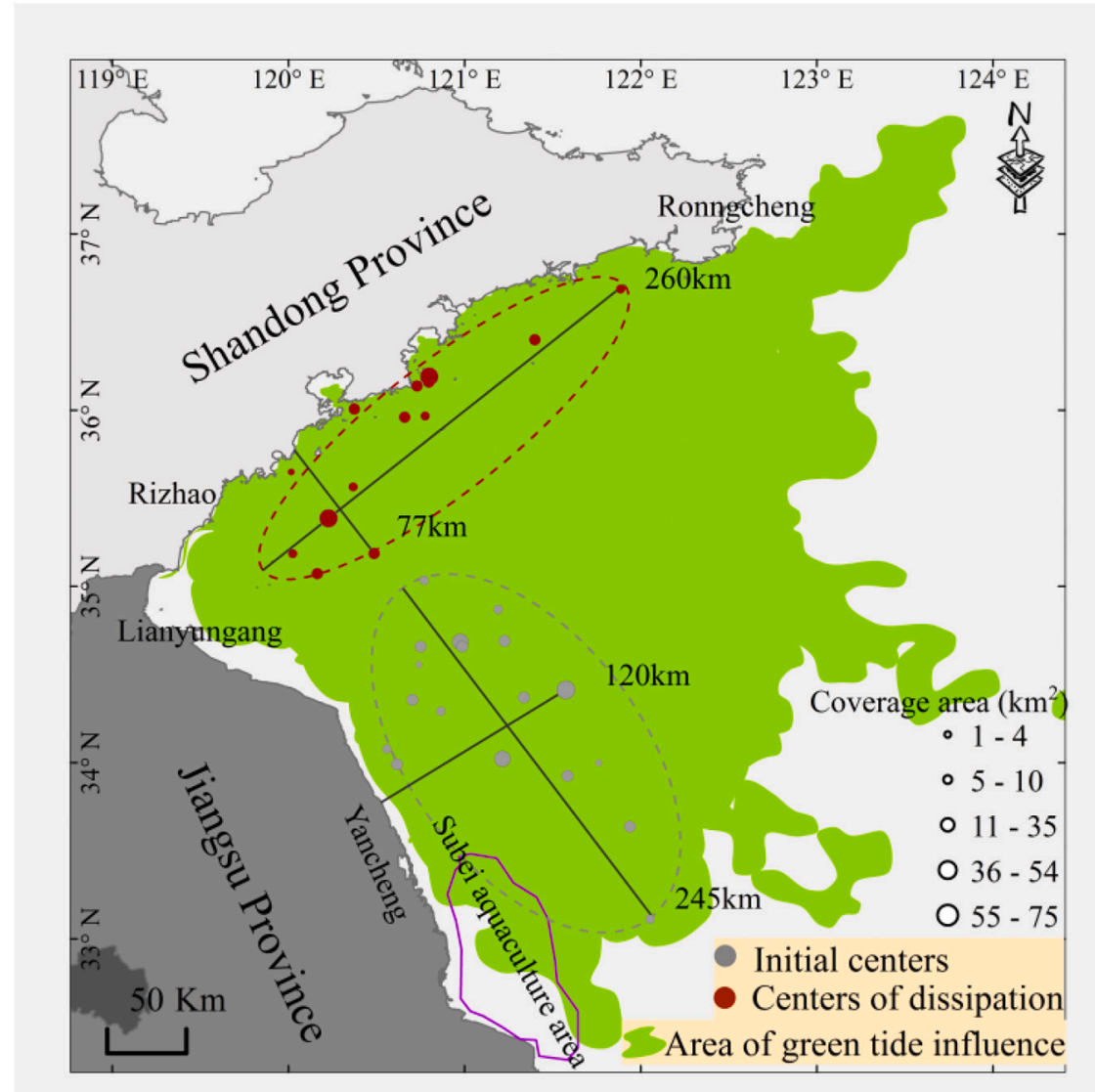

Fig. 4. Schematic diagram of the distribution of green tides from 2007 to 2020 . The gray dots are the initial centers of green tides over the 14 year study period. Red dots are the centers of dissipation for the green tides over the 14-year study period. The green area is the area of green tide influence from 2007 to 2020 . (For interpretation of the references to color in this figure legend, the reader is referred to the web version of this article.) 

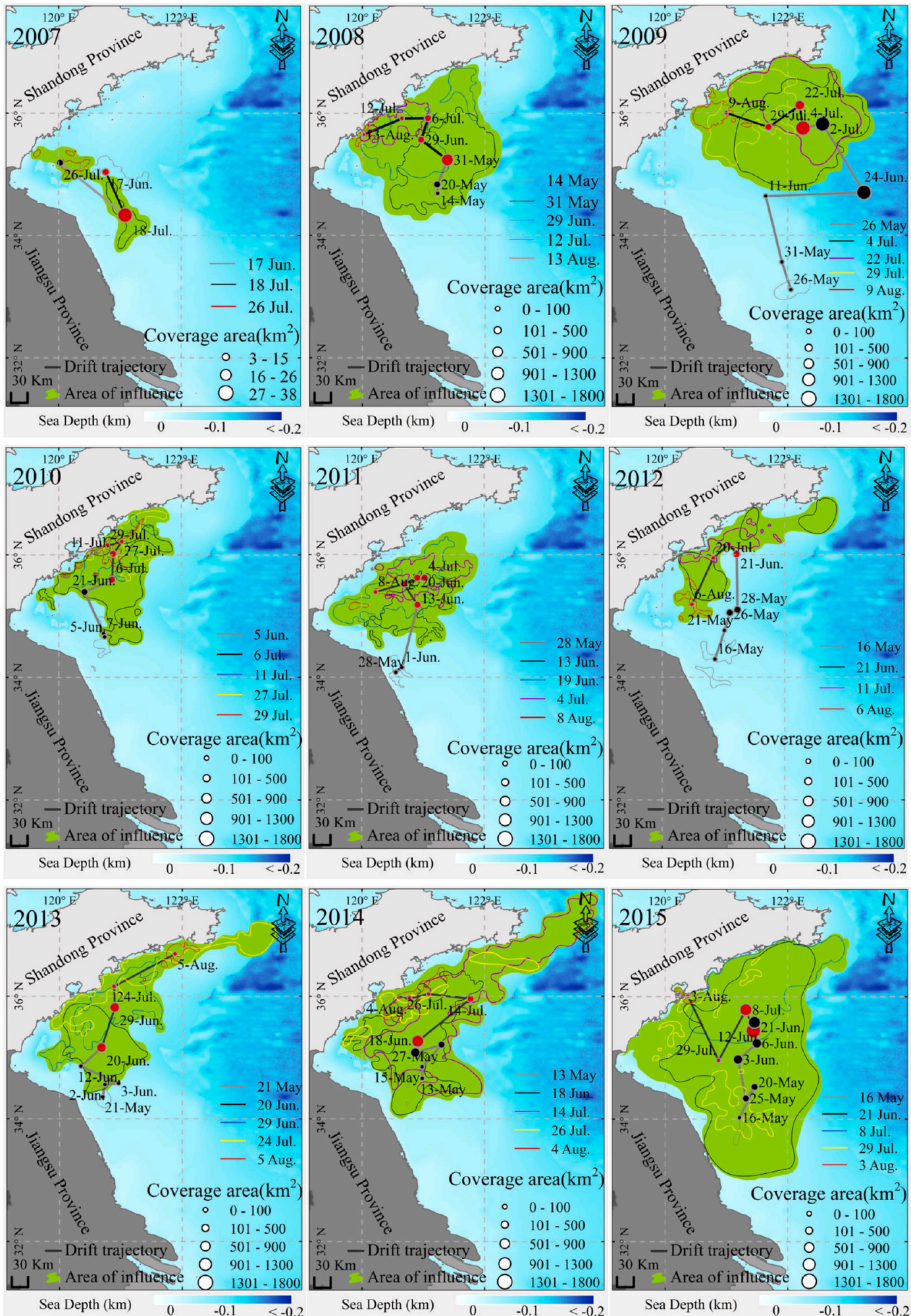

Fig. 5. The dissipation of green tides between 2007 and 2020. The dots represent the central positions of the area covered by green tides, as monitored by satellite on specific dates, and the line connecting the dots represents the drift path of the green tide. The black dots and the gray line indicate the distribution from the initial date to the maximum areas of coverage date. The red dots and the black line indicate the distribution in dissipation period. The green area is annual dissipation area of the green tide. The differently colored solid lines of are the boundary of the area covered by green tides on different dates, in chronological order: black, blue, purple, yellow, and red. The gray boundary line is the boundary of the area covered by green tide on the initial date. (For interpretation of the references to color in this figure legend, the reader is referred to the web version of this article.) 

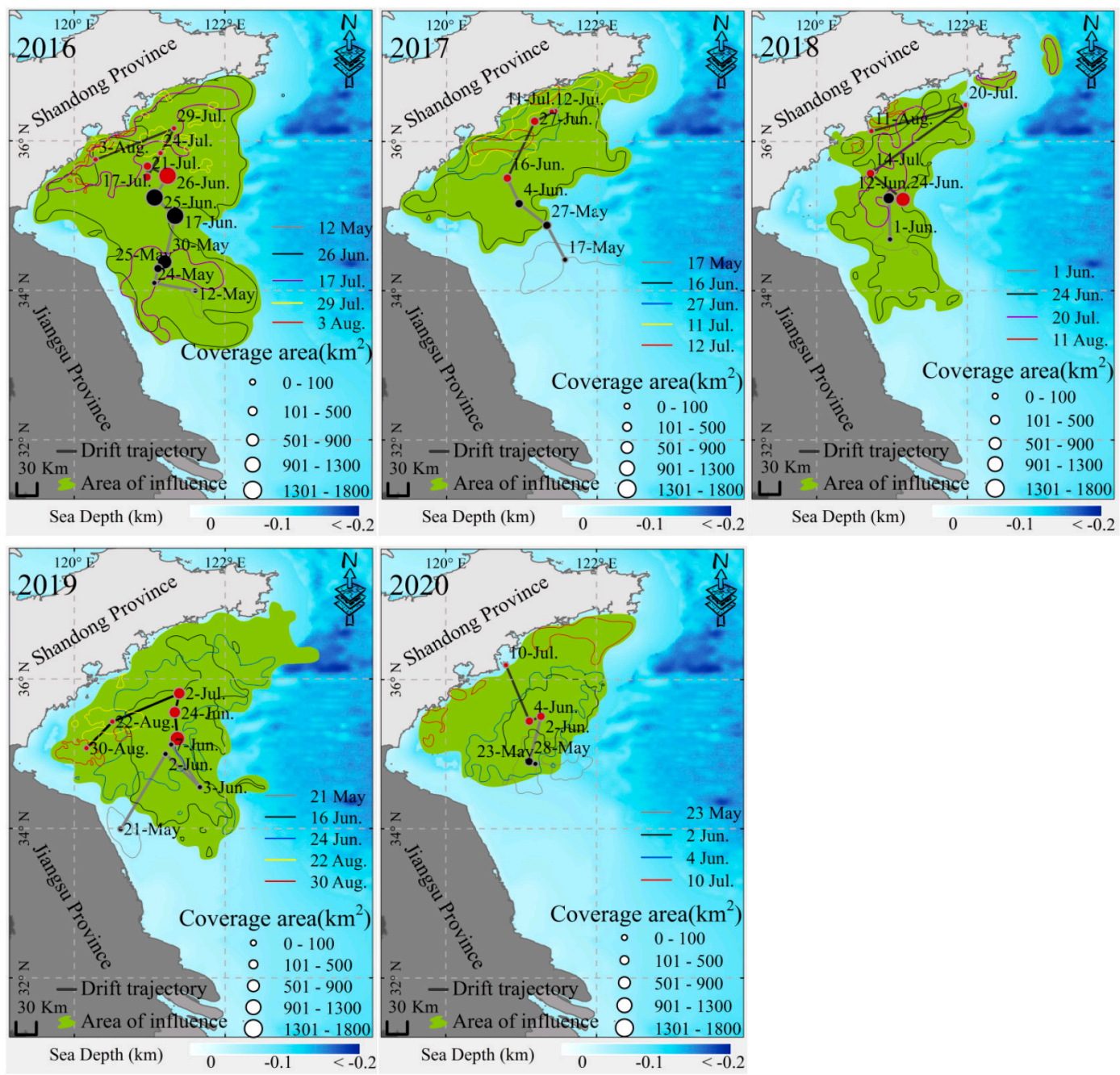

Fig. 5. (continued).

diameter of at least $120 \mathrm{~m}(\mathrm{r}+2 \mathrm{~d})$ (Fig. 2c). When using the value from the center of the cell to convert to raster formats, more than $90 \%$ of the information was effectively retained. The converted S2 and L8 data are shown in Fig. 1c and g; both range and areas of coverages met the requirements of this study.

\subsection{Dissipation area}

In this study, we focused on the process green tide dissipation, defined as the period of time from the date of outbreak till the date of dissipation (hereinafter referred to as the dissipation period) (Fig. 3c). The outbreak date is taken to be the date when the green tide reaches its maximum area of coverage, as monitored by remote sensing images each year. The dissipation date is taken as the date the last monitored remote sensing images are taken, during annual tracking and monitoring processes. According to previous survey data, we know that green tides will continue to persist for about half a month past the date of last monitoring by remote sensing images. To obtain the location and time of the dissipation of the green tides and keep consistent with the data over the years, in this study, we have taken the last date of observation by remote sensing images as the date of dissipation of the green tide every year. The initial date is taken to be the date when the green tide was first detected during the initial phase by satellite.

By comparing the MODIS image interpretation with the cruise observation data, which were collected using the "Ke Xue San Hao" on 17th May, 19th May, and 24th May 2016. We found that within $30 \mathrm{~km}$ outside the green tide boundary monitored by MODIS, there are still green tide patches with a patch size less than $5 \mathrm{~m}$ (magnitude 2), and they are more concentrated within $5 \mathrm{~km}$ of the boundary (Fig. $3 \mathrm{~b}$ ). Therefore, in this study, the annual dissipation area of green tides were defined by adding $5 \mathrm{~km}$ buffer zones around the circumference of the accumulated areas of coverages after merging all the areas covered by green tides during the dissipation period (Fig. 3). Similarly, we merged the areas of coverages of all the green tides from 2007 to 2020, and then added a $5 \mathrm{~km}$ buffer zone around them, and defined that as the area of green tide influence (green area in Fig. 4).

\subsection{Calculation method of environmental factors}

In this study, the calculation area of the regional average was the dissipation area for each corresponding year. The monthly SSW, SSC, and precipitation were averaged across the dissipation period. For example, in 2011, the start and end dates in June were 13th June (the date of outbreak) and 30th June; the start and end dates for July were 1st July and 31st July; and the start and end dates for August were 1st August and 8th August (the date of dissipation), respectively. Here, we focus only on the role of the environmental factors during the dissipation period for green tides in the dissipation area, which can more accurately analyze the relationship between environmental factors and the dissipation of green tides.

The SST was calculated over each natural month. The SST in the Yellow Sea showed an upward trend from June to August, and we had to 


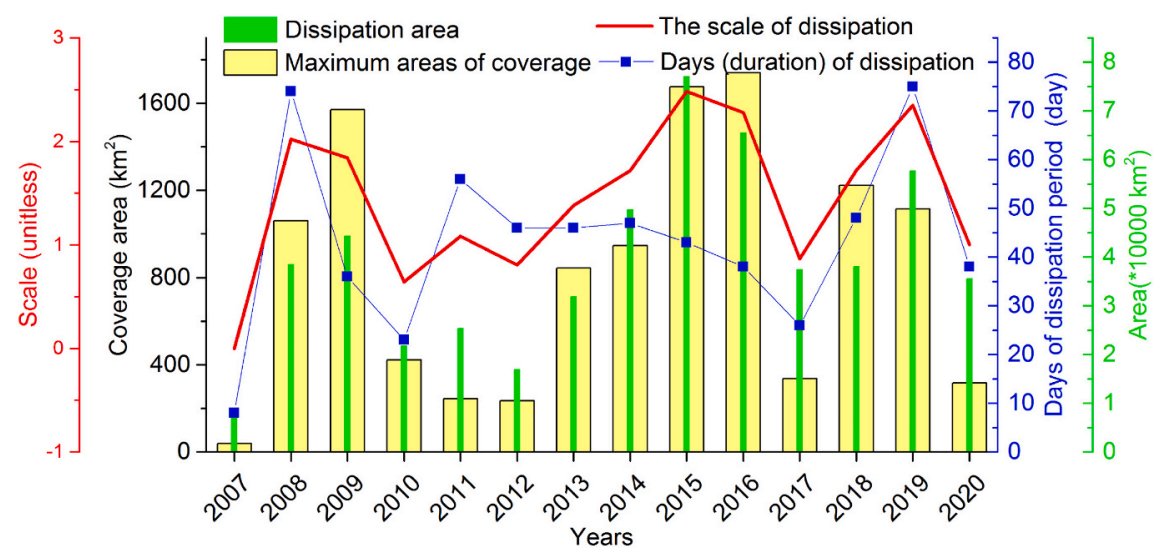

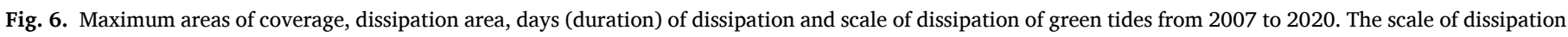

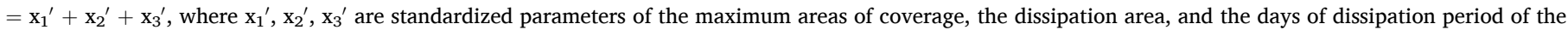
green tide, respectively. (For interpretation of the references to color in this figure legend, the reader is referred to the web version of this article.)

assign a fixed time period for analysis, to ensure the reliability of SST comparison in the dissipation area across different years. In June, the green tides were in their outbreak phase, and the comparison of SST in the dissipation area in this phase over the years was also of great significance for the analysis of the outbreak and dissipation of green tides.

\section{Results}

\subsection{Distribution of green tides from 2007 to 2020}

The center of the area covered by green tide on the initial date was taken as the initial center for that year (the gray dots in Fig. 4). We defined the center of the area covered by green tide on the date of dissipation as the center of dissipation (red dots in Fig. 4).

The area of green tide influence in the Yellow Sea from 2007 to 2020 was up to $116,477 \mathrm{~km}^{2}\left(32-38^{\circ} \mathrm{N}, 119-125^{\circ} \mathrm{E}\right)$. The initial centers of green tide over the past 14 years were in the northeast of the Subei aquaculture area, within an area $120 \mathrm{~km}$ away from the coastline of Jiangsu Province, and within an area $245 \mathrm{~km}$ between Yancheng and Lianyungang. Over the years, the initial dates ranged from May to June, and the area covered by green tide was below $80 \mathrm{~km}^{2}$. The centers of dissipation were $80 \mathrm{~km}$ away from the coastline of Shandong Province, and $260 \mathrm{~km}$ between Rizhao and Rongcheng, the dates of dissipation ranged from July to August, and the area covered by green tide was below $55 \mathrm{~km}^{2}$.

\subsection{Dissipation of green tides from 2007 to 2020}

The temporal and spatial distribution of green tides over their dissipation periods from 2007 to 2020 were obtained, according to the definitions of dissipation period and dissipation area. Their drift paths, areas of coverage, and days (duration) of dissipation period are summarized in Figs. 5 and 6.

It was found that the green tides generally reached their maximum area of coverage in mid-to-late June and early July, and the date of maximum coverage in each year occurs at the end of May (2008), which is consistent with previous studies (Qi et al., 2016; Hu et al., 2017; An, 2020). From mid-June to the end of July, the green tide begins to approach the coastal waters of Rizhao, Qingdao, Haiyang, Rushan, and Rongcheng. Most of the landing dates were within half a month of the date of maximum coverage, and the impact on the coastal waters of the Shandong Peninsula could be as long as 68 days.

From the end of June to the end of July, the green tides reach the northernmost position of the drift sequence $\left(36-38^{\circ} \mathrm{N}, 122-125^{\circ} \mathrm{E}\right)$, and the northernmost position is $37.662^{\circ} \mathrm{N}$ (2014), but there are significant inter-annual differences. Over the years, green tides have reached the northernmost position after the area of coverage reaches its maximum. At these times, the areas of floating green tide algae coverage continue to decrease, the front of the green tide continues to recede from the north to the south, and finally disappears from the sea surface from midJuly to the end of August.

The dissipation period of green tides ranged from 8 to 75 days, with the shortest in 2007 and the longest in 2019. The average dissipation period from 2007 to 2020 were approximately 43 days, and in 2008 , 2011-2015, 2018, and 2019, the dissipation period were more than 43 days (including 43 days). The dissipation periods do not exhibit the same trend as the growth day (the start and end dates of the growth days are the initial date and the maximum area date, respectively) and the maximum area of green tide indicates that the dissipation and growth rates are not the same every year. The dissipation area over the studied years was approximately 8000 to $80,000 \mathrm{~km}^{2}$, with the minimum in $2007\left(8586 \mathrm{~km}^{2}\right)$, and maximum in $2015\left(80,222 \mathrm{~km}^{2}\right)$. There was a linear correlation between the dissipation area and the maximum area of coverage $\left(\mathrm{R}^{2}=0.7171\right)$.

We used the maximum areas of coverage $\left(\mathrm{x}_{1}\right)$, the dissipation area $\left(\mathrm{x}_{2}\right)$, and the days of dissipation period $\left(\mathrm{x}_{3}\right)$ of the green tide to measure the scale of annual green tides during the dissipation period (hereafter referred to as the scale of dissipation), adding the same weights after normalization ( $\mathrm{y}=\mathrm{x}_{1}{ }^{\prime}+\mathrm{x}_{2}{ }^{\prime}+\mathrm{x}_{3}{ }^{\prime}$, where $\mathrm{x}_{1}{ }^{\prime}, \mathrm{x}_{2}{ }^{\prime}, \mathrm{x}_{3}{ }^{\prime}$ are standardized parameters). The scale of dissipation of the green tides over the years presented a "wavy" distribution (solid red line in Fig. 6). The scale of dissipation of the green tide was affected by the initial biomass, environmental conditions (SST, photosynthetically available radiation, nutrients, SSW, SSC, etc.), and human activities (collecting and interception). The summary of the scale of green tide dissipation over the studied years provides data supporting the further investigation of the mechanisms of green tide dissipation.

In 2020, the source of initial green algae biomass in the sea was controlled with measures including algae removal and the timely recovery of seaweed cultivation scaffolding. Monitoring data also shows that the duration, scale, and biomass of green tides in 2020 were far less than those in previous years. Other measures to minimize green tides include reducing the initial biomass of green algae and green algae growth (Kim et al., 2017; Li et al., 2017), detaching green algae from their attachment bases (Fan et al., 2015; Xiao et al., 2020), and the appropriate spatial planning of major cultivation zones (Xing et al., 2019), We also need to continuously monitor the scale of green tide dissipation over the time and continue to comprehensively evaluate the effects of green tide disaster prevention and control measures. 


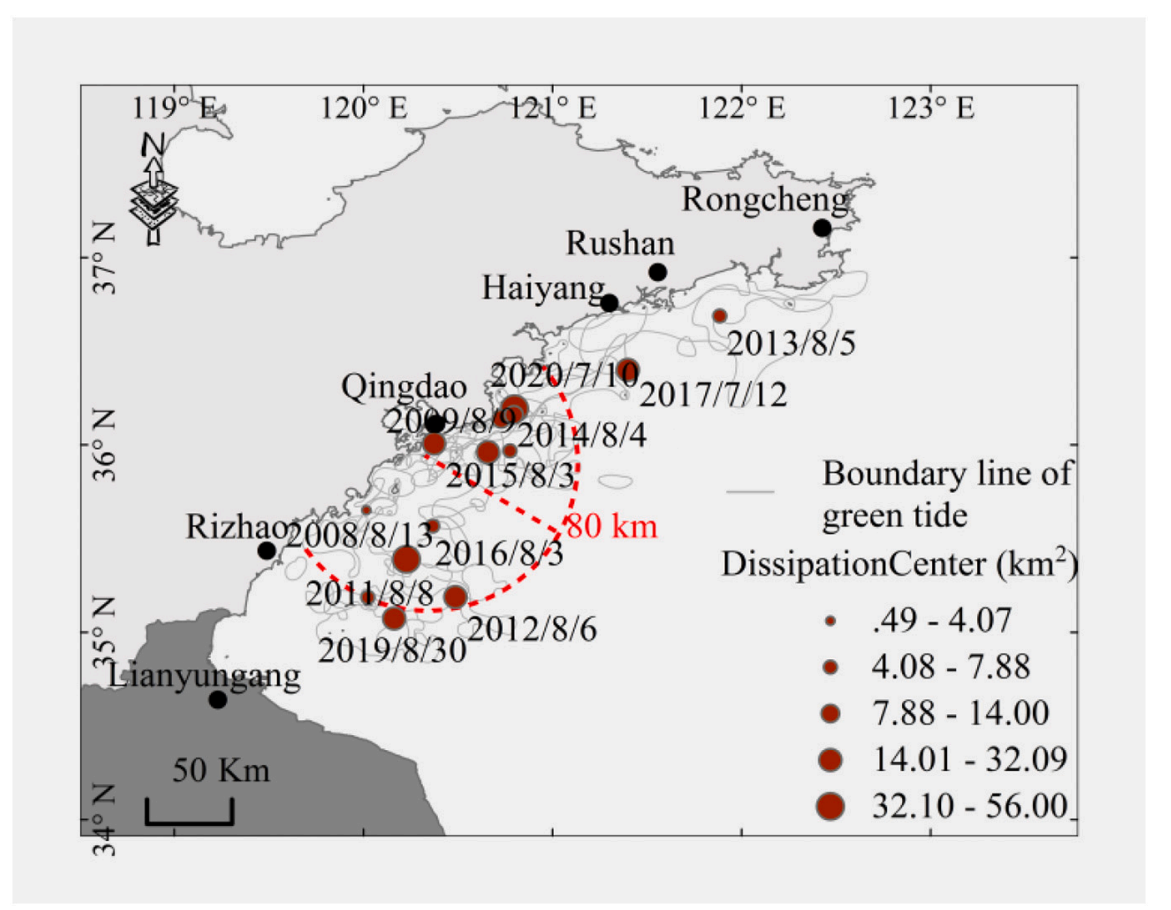

Fig. 7. Dissipation positions of green tides from 2007 to 2020. The solid gray line is the boundary line of annual green tide on the date of dissipation. The red dot is the central position of the area covered by green tide on the annual date of dissipation, and the size indicates the area of coverage at this time. The red dotted line is the area drawn with a radius of $80 \mathrm{~km}$ with Qingdao as the center. (For interpretation of the references to color in this figure legend, the reader is referred to the web version of this article.)
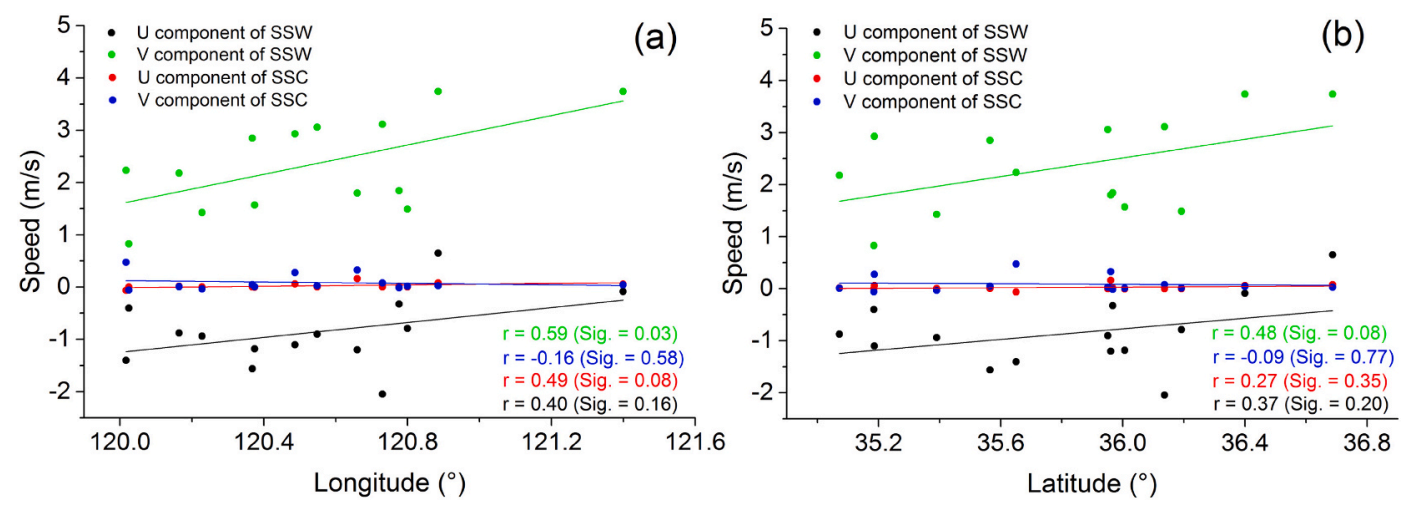

Fig. 8. Correlation analysis between the longitude and latitude of the dissipation location and the average SSW and SSC during the dissipation period. U is the eastwest component of SSW and SSC, and east is the positive direction, V is the north-south component of SSW and SSC, and north is the positive direction. $r$ is the pearson correlation coefficient, Sig. is the significance with the two-tailed test.

\subsection{Spatial distribution of green tides and its relationship with environmental factors}

The centers of dissipation of green tides over the years have been located along the coast of the Shandong Peninsula, mainly with radii of $80 \mathrm{~km}$, with Qingdao as the center. Only in 2013 and 2017, the centers were located north of Qingdao (Fig. 7). Qingdao is an important economic city on the Shandong Peninsula, and the coastal waters of Qingdao are also the most severely affected areas of green tide disasters over the years. Since 2008, Qingdao Municipal Government has organized a large amount of manpower and material resources to collect, intercept and remove green algae along the coast every year. In 2008 alone, the total amount of green algae removed exceeded 800,000 tons (Yu et al., 2018). Understanding the dissipation of the green tide and its environmental factors provides data support for targeted prevention and control the green tide disaster and predicting the dissipation of the green tide.

Through the correlation analysis between the dissipation position and the average SSW and SSC during the dissipation period (Fig. 8), we found that the longitude of the dissipation of the green tide has an obvious positive correlation with the V component of the SSW; that is the greater the north component of SSW, the more eastward the position of green tide drift. There is an obvious positive correlation between the longitude and latitude of green tide drift (Pearson' $r=0.79$, Sig. $=0.001$ (2-tailed)). This is related to the distribution of the coastline of the Shandong Peninsula. Under the influence of the north component of the SSW, the green tide will drift northward, but due to the impact of land barriers and SSC, it actually keeps drifting eastward during the northward process.

There is no correlation between the dissipation position and the average SSC during the dissipation period, but a correlation between them through the monthly average data (Table 1). The east component of the SSC in June and July has an obvious positive correlation with the longitude of the dissipation location.

The centers of green tide dissipation were affected by the combined action of SSW and SSC. In 2013 and 2017, the direction of SSW was mainly southwest, and the direction of SSC was mainly northeast, causing floating green tide to move away from the shore and drift northward. In years where the centers of dissipation were within $80 \mathrm{~km}$ of Qingdao, the direction of SSW was all southeast or northeast; that is, they all moved towards the shore and drift southward. 
Table 1

Correlation analysis between the longitude and latitude of the dissipation location and the monthly average SSW and SSC.

\begin{tabular}{|c|c|c|c|c|c|c|c|c|c|c|c|c|c|c|c|}
\hline & & Lon & Lat & WU6 & wV6 & wU7 & WV7 & WU8 & WV8 & CU6 & CV6 & CU7 & CV7 & CU8 & CV8 \\
\hline \multirow[t]{2}{*}{ Lon } & $\mathrm{r}$ & 1 & $0.788^{* * *}$ & 0.448 & 0.243 & 0.440 & $0.619^{*}$ & 0.112 & -0.081 & 0.654 & -0.434 & $0.536^{*}$ & 0.120 & 0.125 & 0.193 \\
\hline & Sig. & & 0.001 & 0.167 & 0.472 & 0.115 & 0.018 & 0.759 & 0.824 & 0.029 & 0.182 & 0.048 & 0.682 & 0.731 & 0.594 \\
\hline \multirow[t]{2}{*}{ Lat } & $r$ & $0.788^{* *}$ & 1 & 0.413 & 0.022 & 0.288 & 0.428 & 0.522 & 0.318 & 0.273 & -0.106 & 0.232 & -0.193 & 0.185 & 0.102 \\
\hline & Sig. & 0.001 & & 0.206 & 0.949 & 0.318 & 0.127 & 0.121 & 0.370 & 0.416 & 0.755 & 0.425 & 0.508 & 0.609 & 0.779 \\
\hline \multirow[t]{2}{*}{ wU6 } & $\mathrm{r}$ & 0.448 & 0.413 & 1 & 0.456 & -0.039 & 0.227 & -0.002 & -0.542 & 0.559 & -0.341 & 0.008 & -0.383 & -0.640 & -0.638 \\
\hline & Sig. & 0.167 & 0.206 & & 0.159 & 0.910 & 0.503 & 0.997 & 0.131 & 0.074 & 0.304 & 0.981 & 0.244 & 0.064 & 0.065 \\
\hline \multirow[t]{2}{*}{ WV6 } & $\mathrm{r}$ & 0.243 & 0.022 & 0.456 & 1 & 0.030 & $0.663^{*}$ & -0.417 & -0.160 & 0.506 & -0.160 & 0.276 & 0.160 & -0.237 & 0.156 \\
\hline & Sig. & 0.472 & 0.949 & 0.159 & & 0.931 & 0.026 & 0.264 & 0.681 & 0.112 & 0.638 & 0.411 & 0.638 & 0.539 & 0.689 \\
\hline \multirow[t]{2}{*}{ wU7 } & $\mathrm{r}$ & 0.440 & 0.288 & -0.039 & 0.030 & 1 & 0.285 & 0.320 & 0.018 & 0.181 & -0.112 & $0.758^{* *}$ & 0.003 & 0.134 & 0.076 \\
\hline & Sig. & 0.115 & 0.318 & 0.910 & 0.931 & & 0.323 & 0.367 & 0.960 & 0.593 & 0.743 & 0.002 & 0.992 & 0.711 & 0.835 \\
\hline \multirow[t]{2}{*}{ wV7 } & $\mathrm{r}$ & $0.619^{*}$ & 0.428 & 0.227 & $0.663^{*}$ & 0.285 & 1 & -0.156 & 0.021 & 0.353 & 0.029 & $0.619^{*}$ & 0.465 & -0.239 & -0.146 \\
\hline & Sig. & 0.018 & 0.127 & 0.503 & 0.026 & 0.323 & & 0.666 & 0.954 & 0.287 & 0.934 & 0.018 & 0.094 & 0.505 & 0.688 \\
\hline \multirow[t]{2}{*}{ WU8 } & $\mathrm{r}$ & 0.112 & 0.522 & -0.002 & -0.417 & 0.320 & -0.156 & 1 & 0.540 & 0.021 & -0.128 & 0.023 & -0.475 & -0.191 & -0.435 \\
\hline & Sig. & 0.759 & 0.121 & 0.997 & 0.264 & 0.367 & 0.666 & & 0.107 & 0.958 & 0.742 & 0.950 & 0.166 & 0.598 & 0.209 \\
\hline \multirow[t]{2}{*}{ WV8 } & $\mathrm{r}$ & -0.081 & 0.318 & -0.542 & -0.160 & 0.018 & 0.021 & 0.540 & 1 & -0.144 & 0.085 & -0.048 & 0.004 & 0.269 & 0.008 \\
\hline & Sig. & 0.824 & 0.370 & 0.131 & 0.681 & 0.960 & 0.954 & 0.107 & & 0.711 & 0.827 & 0.896 & 0.991 & 0.452 & 0.983 \\
\hline \multirow[t]{2}{*}{ CU6 } & $\mathrm{r}$ & 0.654 & 0.273 & 0.559 & 0.506 & 0.181 & 0.353 & 0.021 & -0.144 & 1 & $-0.883^{* *}$ & 0.386 & 0.034 & -0.150 & -0.032 \\
\hline & Sig. & 0.029 & 0.416 & 0.074 & 0.112 & 0.593 & 0.287 & 0.958 & 0.711 & & 0.000 & 0.241 & 0.922 & 0.701 & 0.935 \\
\hline \multirow[t]{2}{*}{ CV6 } & $\mathrm{r}$ & -0.434 & -0.106 & -0.341 & -0.160 & -0.112 & 0.029 & -0.128 & 0.085 & $-0.883^{* *}$ & 1 & -0.307 & -0.072 & 0.001 & 0.010 \\
\hline & Sig. & 0.182 & 0.755 & 0.304 & 0.638 & 0.743 & 0.934 & 0.742 & 0.827 & 0.000 & & 0.358 & 0.834 & 0.997 & 0.979 \\
\hline \multirow[t]{2}{*}{ CU7 } & $r$ & $0.536^{*}$ & 0.232 & 0.008 & 0.276 & $0.758^{* *}$ & $0.619^{*}$ & 0.023 & -0.048 & 0.386 & -0.307 & 1 & $0.536^{*}$ & -0.021 & 0.012 \\
\hline & Sig. & 0.048 & 0.425 & 0.981 & 0.411 & 0.002 & 0.018 & 0.950 & 0.896 & 0.241 & 0.358 & & 0.048 & 0.955 & 0.974 \\
\hline \multirow[t]{2}{*}{ CV7 } & $\mathrm{r}$ & 0.120 & -0.193 & -0.383 & 0.160 & 0.003 & 0.465 & -0.475 & 0.004 & 0.034 & -0.072 & $0.536^{*}$ & 1 & -0.152 & -0.053 \\
\hline & Sig. & 0.682 & 0.508 & 0.244 & 0.638 & 0.992 & 0.094 & 0.166 & 0.991 & 0.922 & 0.834 & 0.048 & & 0.676 & 0.885 \\
\hline \multirow[t]{2}{*}{ CU8 } & $\mathrm{r}$ & 0.125 & 0.185 & -0.640 & -0.237 & 0.134 & -0.239 & -0.191 & 0.269 & -0.150 & 0.001 & -0.021 & -0.152 & 1 & $0.951^{* *}$ \\
\hline & Sig. & 0.731 & 0.609 & 0.064 & 0.539 & 0.711 & 0.505 & 0.598 & 0.452 & 0.701 & 0.997 & 0.955 & 0.676 & & 0.000 \\
\hline \multirow[t]{2}{*}{ CV8 } & $\mathrm{r}$ & 0.193 & 0.102 & -0.638 & 0.156 & 0.076 & -0.146 & -0.435 & 0.008 & -0.032 & 0.010 & 0.012 & -0.053 & $0.951^{* * *}$ & 1 \\
\hline & Sig. & 0.594 & 0.779 & 0.065 & 0.689 & 0.835 & 0.688 & 0.209 & 0.983 & 0.935 & 0.979 & 0.974 & 0.885 & 0.000 & \\
\hline
\end{tabular}

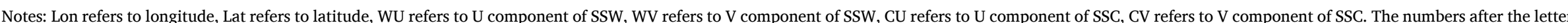

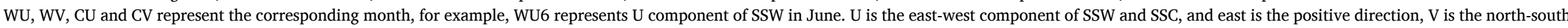
component of SSW and SSC, and north is the positive direction. $r$ is the pearson correlation coefficient, Sig. is the significance with the two-tailed test.

Correlation is significant at the 0.01 level (2-tailed).

* Correlation is significant at the 0.05 level (2-tailed). 


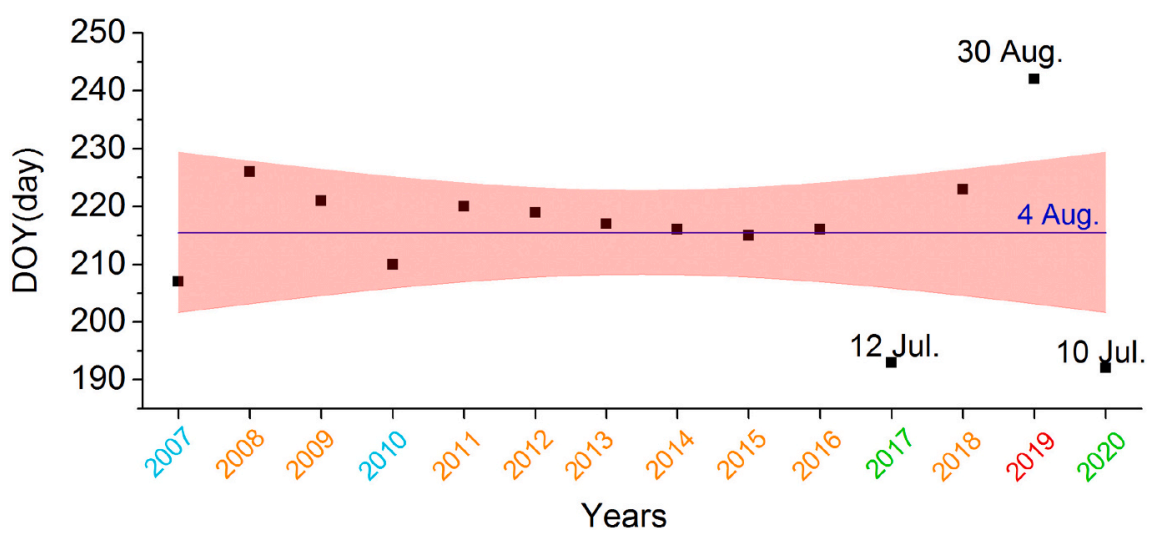

Fig. 9. Distribution of the dates of dissipation of green tides from 2007 to 2020 , the blue solid line is the average of the distribution dates, and the red area is the $95 \%$ confidence interval. For the year marked in green, the date of dissipation was before 26th July. For the year marked in cyan, the date of dissipation was between 26th July. and 4th August. For the year marked in orange, the date of dissipation was between 4th August. and 13th August. For the year marked in red, the date of dissipation was after 13th August. (For interpretation of the references to color in this figure legend, the reader is referred to the web version of this article.)
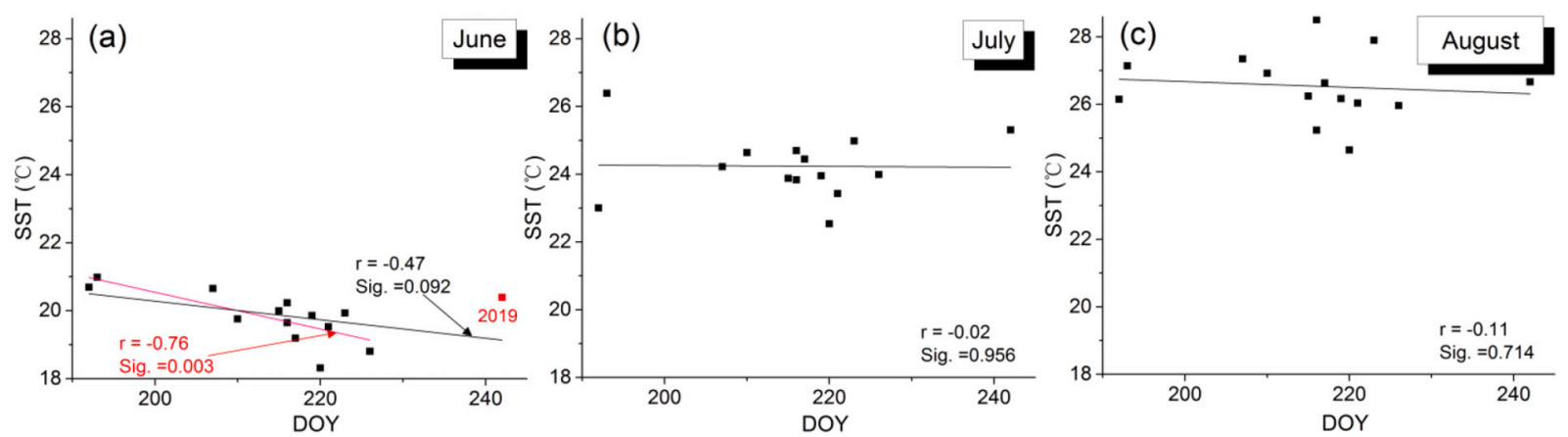

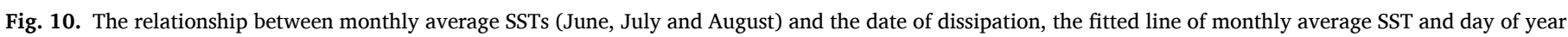

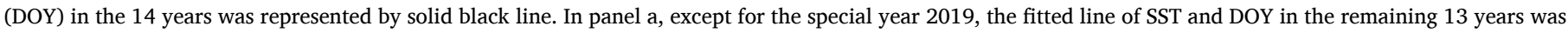

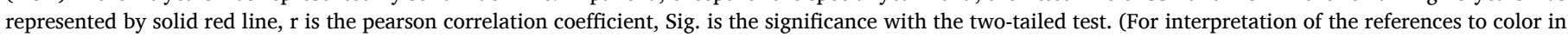
this figure legend, the reader is referred to the web version of this article.)

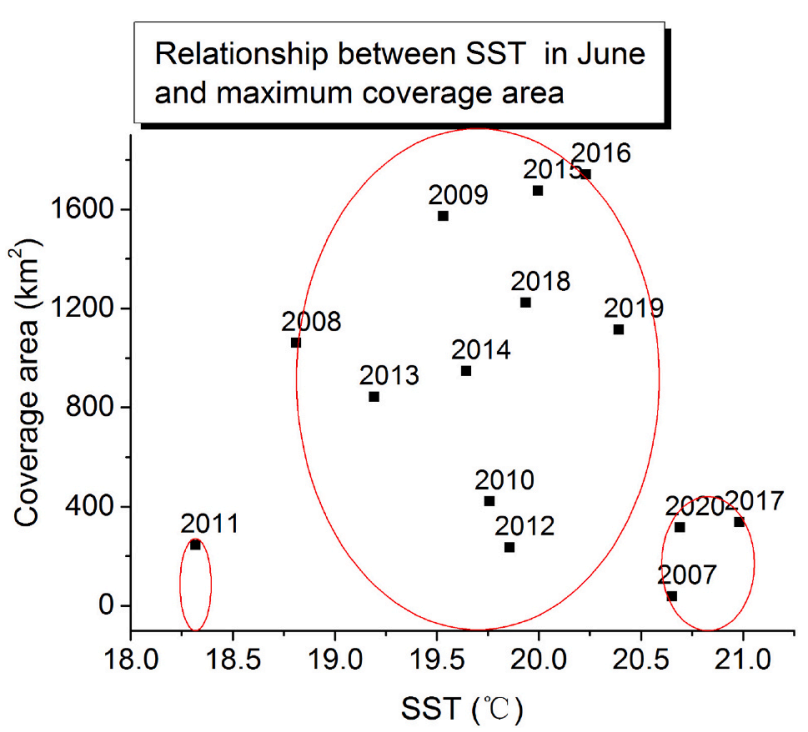

Fig. 11. The relationship between SST in June and the maximum area of green tide coverage from 2007 to 2020. (For interpretation of the references to color in this figure legend, the reader is referred to the web version of this article.)

\subsection{Temporal distribution of green tides and its relationship with environmental factors}

The dates of dissipation were mainly between 26th July to 13th August, and mainly around 4th August (Fig. 9). In 2017 and 2020, the date of dissipation was before 26th July. In 2019, the date of dissipation

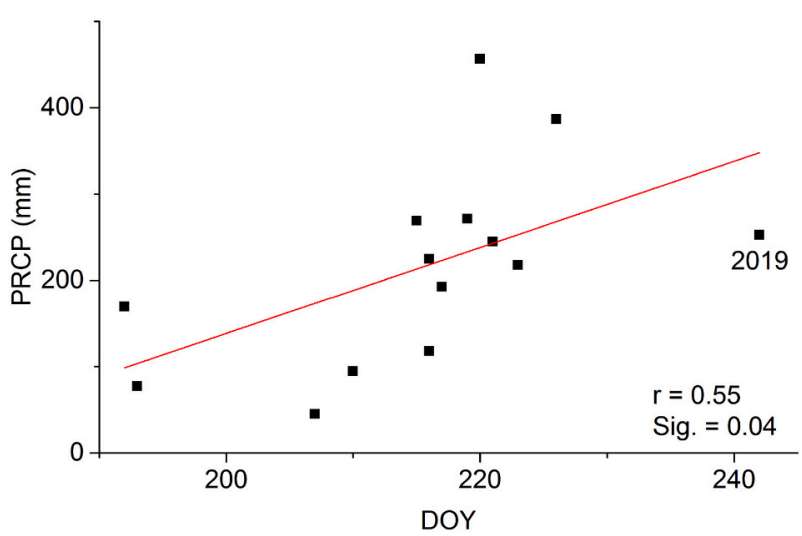

Fig. 12. The relationship between cumulative precipitation of the dissipation area in the dissipation period and the date of dissipation, the fitted line of cumulative precipitation and DOY in the 14 years was represented by solid red line. $\mathrm{r}$ is the pearson correlation coefficient, Sig. is the significance with the two-tailed test. (For interpretation of the references to color in this figure legend, the reader is referred to the web version of this article.)

was after 13th August.

In the dissipation area, the monthly average SST in June is $18-21^{\circ} \mathrm{C}$, the monthly average SST in July is $22-26.5^{\circ} \mathrm{C}$, and the monthly average SST in August is $24.5-28.5{ }^{\circ} \mathrm{C}$. Except for 2019 , there was a negative correlation between the monthly mean SST in June and the date of dissipation, but no significant correlation between SST in July and August and date of dissipation (Fig. 10).

In the years with high SST in June and green tides with earlier dates 
Table 2

Correlation analysis of environmental variables in dissipation period of dissipation area.

\begin{tabular}{|c|c|c|c|c|c|c|c|c|c|c|}
\hline & & Lon & Lat & D_Date & SST & PRCP & WUA & WVA & CUA & CVA \\
\hline \multirow[t]{2}{*}{ Lon } & $\mathrm{r}$ & 1 & $0.788^{* *}$ & $-0.566^{*}$ & 0.306 & -0.466 & 0.402 & $0.588^{*}$ & 0.488 & -0.163 \\
\hline & Sig. & & 0.001 & 0.035 & 0.288 & 0.093 & 0.155 & 0.027 & 0.077 & 0.578 \\
\hline \multirow[t]{2}{*}{ Lat } & $\mathrm{r}$ & $0.788^{* *}$ & 1 & -0.481 & 0.118 & -0.308 & 0.367 & 0.481 & 0.272 & -0.087 \\
\hline & Sig. & 0.001 & & 0.081 & 0.687 & 0.283 & 0.197 & 0.082 & 0.347 & 0.769 \\
\hline \multirow[t]{2}{*}{ D_Date } & $\mathrm{r}$ & $-0.566^{*}$ & -0.481 & 1 & -0.201 & $0.553^{*}$ & -0.347 & -0.032 & -0.046 & 0.290 \\
\hline & Sig. & 0.035 & 0.081 & & 0.491 & 0.040 & 0.224 & 0.914 & 0.875 & 0.314 \\
\hline \multirow[t]{2}{*}{ SST } & $\mathrm{r}$ & 0.306 & 0.118 & -0.201 & 1 & -0.639 & -0.010 & 0.481 & 0.006 & -0.215 \\
\hline & Sig. & 0.288 & 0.687 & 0.491 & & 0.014 & 0.972 & 0.082 & 0.984 & 0.461 \\
\hline \multirow[t]{2}{*}{ PRCP } & $\mathrm{r}$ & -0.466 & -0.308 & $0.553^{*}$ & -0.639 & 1 & -0.433 & -0.169 & -0.167 & 0.430 \\
\hline & Sig. & 0.093 & 0.283 & 0.040 & 0.014 & & 0.122 & 0.564 & 0.567 & 0.125 \\
\hline \multirow[t]{2}{*}{ WUA } & $\mathrm{r}$ & 0.402 & 0.367 & -0.347 & -0.010 & -0.433 & 1 & 0.165 & 0.303 & -0.375 \\
\hline & Sig. & 0.155 & 0.197 & 0.224 & 0.972 & 0.122 & & 0.573 & 0.292 & 0.186 \\
\hline \multirow[t]{2}{*}{ WVA } & $\mathrm{r}$ & $0.588^{*}$ & 0.481 & -0.032 & 0.481 & -0.169 & 0.165 & 1 & 0.223 & 0.129 \\
\hline & Sig. & 0.027 & 0.082 & 0.914 & 0.082 & 0.564 & 0.573 & & 0.443 & 0.660 \\
\hline \multirow[t]{2}{*}{ CUA } & $\mathrm{r}$ & 0.488 & 0.272 & -0.046 & 0.006 & -0.167 & 0.303 & 0.223 & 1 & 0.136 \\
\hline & Sig. & 0.077 & 0.347 & 0.875 & 0.984 & 0.567 & 0.292 & 0.443 & & 0.642 \\
\hline \multirow[t]{2}{*}{ CVA } & $\mathrm{r}$ & -0.163 & -0.087 & 0.290 & -0.215 & 0.430 & -0.375 & 0.129 & 0.136 & 1 \\
\hline & Sig. & 0.578 & 0.769 & 0.314 & 0.461 & 0.125 & 0.186 & 0.660 & 0.642 & \\
\hline
\end{tabular}

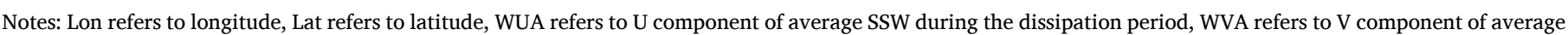

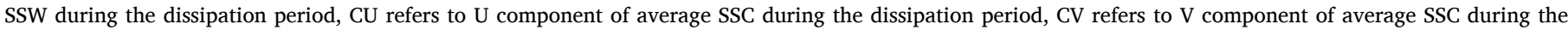

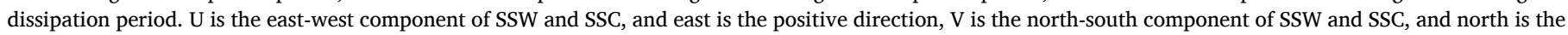
positive direction. D_Date refers to the date of dissipation. $\mathrm{r}$ is the pearson correlation coefficient, Sig. is the significance with the two-tailed test.

*** Correlation is significant at the 0.01 level (2-tailed).

* Correlation is significant at the 0.05 level (2-tailed).

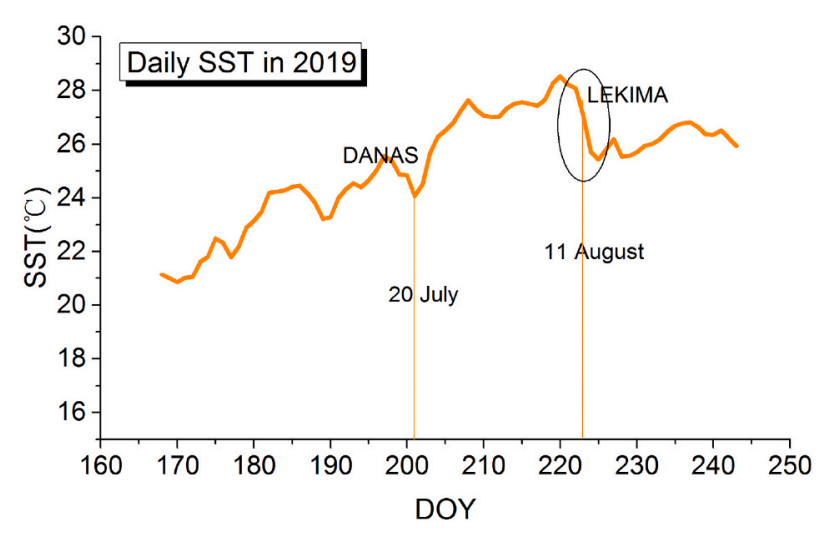

Fig. 13. The daily SST of the dissipation area in the dissipation period in 2019 . The date labels are typhoon DANAS on 20th July 2019, and typhoon LEKIMA on 11th August 2019.

of dissipation (for example, 2007, 2017 and 2020), the SST in the dissipation area was $20.5{ }^{\circ} \mathrm{C}$ or above in June, and the dates of dissipation in 2007, 2017 and 2020 were before (and including) 26th July.

In June, green tides are in their outbreak phase, and the SST in this phase was $18.5-20.5{ }^{\circ} \mathrm{C}$ (Fig. 11) for most years, without considering other factors. It was speculated that the higher SST in June may limit the growth of the green tide and accelerate earlier transitions into the dissipation phase.

There was a positive correlation between precipitation and date of dissipation. The year with greatest accumulated precipitation had a later date of dissipation (Fig. 12), precipitation can temporarily increase the concentrations of nutrients in surface seawater, which may promote the growth of green tide algae.

In conclusion, the year with the highest SST in June had an earlier date of dissipation, the year with greatest accumulated precipitation had a later date of dissipation; that is, high SSTs accelerated the dissipation of green tides, and precipitation during the dissipation period slows down the dissipation of green tides.

\section{Discussion}

\subsection{Interaction among environmental factors}

There was a negative correlation between the average SST and accumulated precipitation in dissipation period of dissipation area; that is the greater the precipitation, the lower the SST. This is maybe due to the cloud during precipitation reduces the solar radiation received by the surface of the water body, and the temperature of the weather decreases. There is a correlation between the monthly average SSW and SSC (Table 1), but no correlation between the average SSW and SSC during the dissipation period (Table 2).

\subsection{The combined effect of SST and PRCP influencing temporal distribution}

The average SST and accumulated precipitation in dissipation period of dissipation area are negatively correlated. The greater PRCP prolonged the dissipation period of the green tide, and the higher SST in June shortened it. However, in 2019, we found that its SST in June was relatively high (Fig. 10a), and its accumulated precipitation was not very large (Fig. 12). Why was its dissipation period so long?

In 2019, influenced by typhoon DANAS on 20th July and typhoon LEKIMA on 11th August, the SST fluctuates greatly in a short time (about $1.5-3{ }^{\circ} \mathrm{C}$ ) (Fig. 13), especially under the influence of LEKIMA, the disturbance of the typhoon may cause the low-temperature nutrient water at the bottom to enter the surface, the area covered by green tide increases again during dissipation, which prolonged the dissipation period of the green tide in 2019 when the precipitation was not particularly abundant. This shows that SST plays a key role in the joint action of SST and precipitation.

\subsection{Future work}

The coastal waters of the Yellow Sea, especially the origin of the green tide, the coastal waters of Jiangsu, where the waters are turbid, eutrophic, and optically complex (Lei, 2011). Different atmospheric correction methods have a certain impact on the results of the Yellow Sea green tide extraction (Zheng et al., 2017), and the atmospheric correction has been challenging over optically complex and turbid 
coastal waters (Hu et al., 2017; Hu et al., 2019). Currently, there is no highly accurate atmospheric correction data (Shen et al., 2019)。 .

ACOLITE and SeaDAS are specifically designed for atmospheric correction over water surfaces and can be applied to S2 and L8 (Ilori et al., 2019), the SWIR atmospheric correction method is for MODIS top of atmosphere radiance (Wang and Shi, 2007; Wang et al., 2009), and a correction method for the MODIS surface reflectance product (Wang et al., 2016).

The above atmospheric correction methods have improved the accuracy of remote sensing reflectance of water bodies, but these methods are not yet integrated into the GEE platform. In order to further improve the accuracy of quantitative green tide disaster monitoring, a lot of efforts need to be made in regional atmospheric correction methods combined with in situ measurements. At the same time, the integration of different atmospheric correction methods into the GEE platform enables GEE to add advantages for regional applications to the advantages of global large-scale applications.

\section{Conclusion}

In this study, the green tide information extracted from multi-source satellites was consistently processed, and information about the date of dissipation, areas of coverage, dissipation area, dissipation path, and dissipation period of the green tides in the Yellow Sea from 2007 to 2020 were obtained from S2, L5, and L8 assisted MODIS data. The main environmental factors influencing the temporal and spatial distribution of the green tide dissipation were analyzed, and the main conclusions are as follows.

(1) The scale of dissipation of the green tide over the 14 studied years showed a "wavy" pattern. The centers of dissipation were mainly in the $80 \mathrm{~km}$ sea area centered on Qingdao, and the dates of dissipation were mainly between 26th July and 13th August.

(2) The spatial distribution of the dissipation of the green tide was influenced by the combined action of the SSW and SSC. The floating green tide moved seawards because of the action of the SSW and SSC in the northeast direction, and the center of dissipation was north of Qingdao. Under the action of SSW and SSC pointing to the northwest or southwest, the floating green tide moved shoreward, and the center of dissipation was south of Qingdao.

(3) The temporal distribution of green tide dissipations were influenced by the combined effects of SST and precipitation. The high SST accelerated the dissipation of green tides, and precipitation during the dissipation periods slowed down the dissipation of green tides.

However, the marine environment is very complex and changeable, and there are many other factors that influence the dissipation of green tides. The results of this study could be helpful in further understanding the dissipation mechanisms of green tides in the Yellow Sea.

\section{CRediT authorship contribution statement}

Dongxue Li: Data curation, Methodology, Visualization, Writing original draft, Validation. Zhiqiang Gao: Supervision, Conceptualization, Investigation, Writing - review \& editing. Fuxiang Xu: Methodology.

\section{Declaration of competing interest}

The authors declare that they have no known competing financial interests or personal relationships that could have appeared to influence the work reported in this paper.

\section{Acknowledgments}

This work was supported from NSFC (41876107), Key Deployment Project of Center for Ocean Mega-Science, Chinese Academy of Sciences (COMS2019J02), Key Research Program of Frontier Science, Chinese Academy of Sciences (ZDBS-LY-7010), Open Fund of CAS Key Laboratory of Marine Ecology and Environmental Sciences (KLMEES202005), CAS Key Laboratory of Coastal Environmental Processes and Ecological Remediation (2019SDHADKFJJ11).

\section{Appendix A. Supplementary data}

Supplementary data to this article can be found online at https://doi. org/10.1016/j.marpolbul.2021.112801.

\section{References}

An, D., 2020. The spatiotemporal variation research of Ulva prolifera blooms dissipation in the southern Yellow Sea Doctor Yantai Institute of Coastal Zone Research. Chinese Academy of Sciences. https://doi.org/10.27841/d.cnki.gytha.2020.000011 (In Chinese with English abstract).

Bao, M., Guan, W., Yang, Y., Cao, Z., Chen, Q., 2015. Drifting trajectories of green algae in the western Yellow Sea during the spring and summer of 2012. Estuar. Coast. Shelf Sci. 163, 9-16. https://doi.org/10.1016/j.ecss.2015.02.009.

Bermejo, R., Heesch, S., Mac Monagail, M., O'donnell, M., Daly, E., Wilkes, R.J., Morrison, L., 2019. Spatial and temporal variability of biomass and composition of green tides in Ireland. Harmful Algae 81, 94-105. https://doi.org/10.1016/j. hal.2018.11.015.

Chen, X., Liu, L., Zhang, X., Li, J., Wang, S., Liu, D., Duan, H., Song, K., 2021. An assessment of water color for inland water in China using a landsat 8-derived Forel? Ule index and the Google earth engine platform. IEEE J. Sel. Top. Appl. Earth Observations Remote Sens. https://doi.org/10.1109/JSTARS.2021.3085411.

Chimney, M.J., Pietro, K.C., 2006. Decomposition of macrophyte litter in a subtropical constructed wetland in South Florida (USA). Ecol. Eng. 27, 301-321. https://doi. org/10.1016/j.ecoleng.2006.05.016.

Cui, T., Zhang, J., Sun, L., Jia, Y., Zhao, W., Wang, Z., Meng, J., 2012. Satellite monitoring of massive green macroalgae bloom (GMB): imaging ability comparison of multi-source data and drifting velocity estimation. Int. J. Remote Sens. 33, 5513-5527. https://doi.org/10.1080/01431161.2012.663112.

Cui, T.W., Zhang, J., Tang, J.W., Sathyendranath, S., Groom, S., Ma, Y., Zhao, W., Song, Q.J., 2014. Assessment of satellite ocean color products of MERIS, MODIS and SeaWiFS along the East China coast (in the Yellow Sea and East China Sea). ISPRS J. Photogramm. Remote Sens. 87, 137-151. https://doi.org/10.1016/j. isprsjprs. 2013.10.013.

Cummings, J.A., Smedstad, O.M., 2013. In: Variational Data Assimilation for the Global Ocean. Data Assimilation for Atmospheric, Oceanic and Hydrologic Applications, II, pp. 303-343. https://doi.org/10.1007/978-3-642-35088-7_13.

Doernhoefer, K., Goeritz, A., Gege, P., Pflug, B., Oppelt, N., 2016. Water constituents and water depth retrieval from sentinel-2A-A first evaluation in an oligotrophic Lake. Remote Sens. 8 https://doi.org/10.3390/rs8110941.

Fan, S., Fu, M., Wang, Z., Zhang, X., Song, W., Li, Y., Liu, G., Shi, X., Wang, X., Zhu, M., 2015. Temporal variation of green macroalgal assemblage on porphyra aquaculture rafts in the Subei Shoal, China. Estuar. Coast. Shelf Sci. 163, 23-28. https://doi.org/ 10.1016/j.ecss.2015.03.016.

Fu, M.Z., Fan, S.L., Wang, Z.L., Song, W., Sun, K.M., Han, H.B., Xiao, J., Shen, S.D., 2019. Buoyancy potential of dominant green macroalgal species in the Yellow Sea\&apos;s green tides, China. Mar. Pollut. Bull. 140, 301-307. https://doi.org/10.1016/j. marpolbul.2019.01.056.

Hu, L.B., Hu, C.M., He, M.X., 2017. Remote estimation of biomass of Ulva prolifera macroalgae in the Yellow Sea. Remote Sens. Environ. 192, 217-227. https://doi.org/ 10.1016/j.rse.2017.01.037.

Hu, L., Zeng, K., Hu, C., He, M.-X., 2019. On the remote estimation of Ulva prolifera areal coverage and biomass. Remote Sens. Environ. 223, 194-207. https://doi.org/ 10.1016/j.rse.2019.01.014.

Huo, Y., Han, H., Hua, L., Wei, Z., Yu, K., Shi, H., Kim, J.K., Yarish, C., He, P., 2016. Tracing the origin of green macroalgal blooms based on the large scale spatiotemporal distribution of Ulva microscopic propagules and settled mature Ulva vegetative thalli in coastal regions of the Yellow Sea, China. Harmful Algae 59, 91-99. https://doi.org/10.1016/j.hal.2016.09.005.

Ilori, C.O., Pahlevan, N., Knudby, A., 2019. Analyzing performances of different atmospheric correction techniques for Landsat 8: application for coastal remote sensing. Remote Sens. 11 https://doi.org/10.3390/rs11040469.

Jin, S., Liu, Y., Sun, C., Wei, X., Li, H., Han, Z., 2018. A study of the environmental factors influencing the growth phases of Ulva prolifera in the southern Yellow Sea, China. Mar. Pollut. Bull. 135, 1016-1025. https://doi.org/10.1016/j. marpolbul.2018.08.035.

Kim, J.-H., Kang, E.J., Park, M.G., Lee, B.-G., Kim, K.Y., 2011. Effects of temperature and irradiance on photosynthesis and growth of a green-tide-forming species (Ulva linza) in the Yellow Sea. J. Appl. Phycol. 23, 421-432. https://doi.org/10.1007/s10811010-9590-y. 
Kim, J.K., Yarish, C., Hwang, E.K., Park, M., Kim, Y., 2017. Seaweed aquaculture: cultivation technologies, challenges and its ecosystem services. Algae 32, 1-13. https://doi.org/10.4490/algae.2017.32.3.3.

Kim, K., Shin, J., Ryu, J., 2018. Application of multi-satellite sensors to estimate the green-tide area. Korean J. Remote. Sens. 34, 339-349. https://doi.org/10.7780/ kjrs.2018.34.2.2.4.

Kong, F., Jiang, P., Wei, C., Zhang, Q., Li, J., Liu, Y., Yu, R., Yan, T., Zhou, M., 2018. Cooccurence of green tide, golden tide and red tides along the $35^{\circ} \mathrm{N}$ transect in the Yellow sea during spring and summer in 2017. Oceanologia et Limnologia Sinica 49, 1021-1030. https://doi.org/10.11693/hyhz20180400082 (In Chinese with English Abstract).

Lei, H., 2011. The Remote Sensing Algorithm of HAB Extraction Based on Inherent Optical Properties in ECS. Doctor Thesis. Zhejiang University, Hangzhou, China, p. 131.

Li, J., Song, X., Zhang, Y., Pan, J., Yu, Z., 2017. An investigation of the space distribution of ulva microscopic propagules and ship-based experiment of mitigation using modified clay. Mar. Pollut. Bull. 117, 247-254. https://doi.org/10.1016/j. marpolbul.2017.01.063.

Liu, D.Y., Keesing, J.K., He, P.M., Wang, Z.L., Shi, Y.J., Wang, Y.J., 2013. The world\&apos;s largest macroalgal bloom in the Yellow Sea, China: formation and implications. Estuar. Coast. Shelf Sci. 129, 2-10. https://doi.org/10.1016/j. ecss.2013.05.021.

Liu, X., Li, Y., Wang, Z., Zhang, Q., Cai, X., 2015. Cruise observation of Ulva prolifera bloom in the southern Yellow Sea, China. Estuar. Coast. Shelf Sci. 163, 17-22. https://doi.org/10.1016/j.ecss.2014.09.014.

Liu, X., Wang, Z., Zhang, X., 2016. A review of the green tides in the Yellow Sea, China. Mar. Environ. Res. 119, 189-196. https://doi.org/10.1016/j. marenvres.2016.06.004.

Main-Knorn, M., Pflug, B., Louis, J., Debaecker, V., Muller-Wilm, U., Gascon, F., 2017. Sen2Cor for Sentinel-2. In: Bruzzone, L., Bovolo, F. (Eds.), Image and Signal Processing for Remote Sensing Xxiii.

Marine Environmental Protection Department of North China Sea Branch of State Oceanic Administration, 2021. Green Tide Bulletin in North China Sea. http://123.2 34.129.76:8088/search1/WebSite/cms/SearchInfoList.aspx? searchContent=\%E7\% BB\%BF\%E6\%BD\%AE.

Qi, L., Hu, C., Xing, Q., Shang, S., 2016. Long-term trend of Ulva prolifera blooms in the western Yellow Sea. Harmful Algae 58, 35-44. https://doi.org/10.1016/j. hal.2016.07.004.

Ramsey III, E., Rangoonwala, A., Thomsen, M.S., Schwarzschild, A., 2012. Spectral definition of the macro-algae Ulva curvata in the back-barrier bays of the Eastern Shore of Virginia, USA. Int. J. Remote Sens. 33, 586-603. https://doi.org/10.1080/ 01431161.2010 .543436

Sayler, K., 2020a. Landsat 4-7 Collection 1 (C1) Surface Reflectance (LEDAPS) Product Guide.

Sayler, K., 2020b. Landsat 8 Collection 1 (C1) Land Surface Reflectance Code (LaSRC) Product Guide.

Schreyers, L., Van Emmerik, T., Biermann, L., Le Lay, Y.F., 2021. Spotting green tides over Brittany from space: three decades of monitoring with Landsat imagery. Remote Sens. 13 https://doi.org/10.3390/rs13081408.

Shen, F., Tang, R., Sun, X., Liu, D., 2019. Simple methods for satellite identification of algal blooms and species using 10-year time series data from the East China Sea. Remote Sens. Environ. 235 https://doi.org/10.1016/j.rse.2019.111484.

Smetacek, V., Zingone, A., 2013. Green and golden seaweed tides on the rise. Nature 504 84-88. https://doi.org/10.1038/nature12860.

Son, Y.B., Choi, B.-J., Kim, Y.H., Park, Y.-G., 2015. Tracing floating green algae blooms in the Yellow Sea and the East China Sea using GOCI satellite data and Lagrangian transport simulations. Remote Sens. Environ. 156, 21-33. https://doi.org/10.1016/ j.rse.2014.09.024.

Taylor, R., Fletcher, R.L., Raven, J.A., 2001. Preliminary studies on the growth of selected \&apos;Green tide\&apos; algae in laboratory culture: effects of irradiance, temperature, salinity and nutrients on growth rate. Bot. Mar. 44, 327-336. https:// doi.org/10.1515/bot.2001.042.

Valiela, I., Mcclelland, J., Hauxwell, J., Behr, P.J., Hersh, D., Foreman, K., 1997. Macroalgal blooms in shallow estuaries: controls and ecophysiological and ecosystem consequences. Limnol. Oceanogr. 42, 1105-1118. https://doi.org/ 10.4319/1o.1997.42.5_part_2.1105.

Vermote, E.F., Vermeulen, A., 1999. Atmospheric Correction Algorithm: Spectral Reflectances (MOD09).

Wang, M., Shi, W., 2007. The NIR-SWIR combined atmospheric correction approach for MODIS Ocean color data processing. Opt. Express 15, 15722-15733. https://doi. org/10.1364/oe.15.015722.
Wang, M., Son, S., Shi, W., 2009. Evaluation of MODIS SWIR and NIR-SWIR atmospheric correction algorithms using SeaBASS data. Remote Sens. Environ. 113, 635-644. https://doi.org/10.1016/j.rse.2008.11.005.

Wang, C., Yu, R.-C., Zhou, M.-J., 2012. Effects of the decomposing green macroalga Ulva (Enteromorpha) prolifera on the growth of four red-tide species. Harmful Algae 16, 12-19. https://doi.org/10.1016/j.hal.2011.12.007.

Wang, S.L., Li, J.S., Zhang, B., Shen, Q., Zhang, F.F., Lu, Z.Y., 2016. A simple correction method for the MODIS surface reflectance product over typical inland waters in China. Int. J. Remote Sens. 37, 6076-6096. https://doi.org/10.1080/ 01431161.2016.1256508.

Wang, W., Zhang, G., Sun, X., Zhang, F., Zhang, X., 2019. Temporal variability in zooplankton community in the western Yellow Sea and its possible links to green tides. PeerJ 7. https://doi.org/10.7717/peerj.6641.

Wang, Q.L., Li, W., Xiao, C., Ai, W.X., 2020. Evaluation of high-resolution crop model meteorological forcing datasets at regional scale: air temperature and precipitation over major land areas of China. Atmosphere 11. https://doi.org/10.3390/ atmos11091011.

Wu, W.F., Li, P.L., Zhai, F.G., Gu, Y.Z., Liu, Z.Z., 2020. Evaluation of different wind resources in simulating wave height for the Bohai, Yellow, and East China Seas (BYES) with SWAN model. Cont. Shelf Res. 207, 14. https://doi.org/10.1016/j. csr.2020.104217.

Xiao, J., Zhang, X., Gao, C., Jiang, M., Li, R., Wang, Z., Li, Y., Fan, S., Zhang, X., 2016. Effect of temperature, salinity and irradiance on growth and photosynthesis of Ulva prolifera. Acta Oceanol. Sin. 35, 114-121. https://doi.org/10.1007/s13131-0160891-0.

Xiao, J., Wang, Z., Song, H., Fan, S., Yuan, C., Fu, M., Miao, X., Zhang, X., Su, R., Hu, C., 2020. An anomalous bi-macroalgal bloom caused by ulva and sargassum seaweeds during spring to summer of 2017 in the western Yellow Sea, China. Harmful Algae 93. https://doi.org/10.1016/j.hal.2020.101760.

Xing, Q., Hu, C., Tang, D., Tian, L., Tang, S., Wang, X., Lou, M., Gao, X., 2015. World's largest macroalgal blooms altered phytoplankton biomass in summer in the Yellow Sea: satellite observations. Remote Sens. 7, 12297-12313. https://doi.org/10.3390/ rs70912297.

Xing, Q.G., An, D.Y., Zheng, X.Y., Wei, Z.N., Wang, X.H., Li, L., Tian, L.Q., Chen, J., 2019. Monitoring seaweed aquaculture in the Yellow Sea with multiple sensors for managing the disaster of macroalgal blooms. Remote Sens. Environ. 231, 12. https:// doi.org/10.1016/j.rse.2019.111279.

Xu, D., Li, X., Zhu, J., Qi, Y., 2011. Evaluation of an ocean data assimilation system for Chinese marginal seas with a focus on the South China Sea. Chin. J. Oceanol. Limnol. 29, 414-426. https://doi.org/10.1007/s00343-011-0044-4.

Xu, Q., Zhang, H., Cheng, Y., 2016. Multi-sensor monitoring of Ulva prolifera blooms in the Yellow Sea using different methods. Frontiers of Earth Science 10, 378-388. https://doi.org/10.1007/s11707-015-0528-1.

Xu, F., Gao, Z., Shang, W., Jiang, X., Zheng, X., Ning, J., Song, D., 2017. Validation of MODIS-based monitoring for a green tide in the Yellow Sea with the aid of unmanned aerial vehicle. J. Appl. Remote. Sens. 11 https://doi.org/10.1117/1. Jrs.11.012007.

Ye, N., Zhang, X., Mao, Y., Liang, C., Xu, D., Zou, J., Zhuang, Z., Wang, Q., 2011. 'Green tides' are overwhelming the coastline of our blue planet: taking the world's largest example. Ecol. Res. 26, 477-485. https://doi.org/10.1007/s11284-011-0821-8.

Yu, R., Sun, S., Yan, T., Zhou, M., 2018. Progresses and perspectives on green-tide studies in the Yellow Sea. Oceanologia et Limnologia Sinica 49, 942-949. https://doi.org/ 10.11693/hyhz20180700158 (In Chinese with English Abstract).

Zhang, G., Wu, M., Zhang, A., Xing, Q., Zhou, M., Zhao, D., Song, X., Yu, Z., 2020. Influence of sea surface temperature on outbreak of Ulva prolifera in the southern Yellow Sea, China. Chin. Geogr. Sci. 30, 631-642. https://doi.org/10.1007/s11769020-1129-9.

Zhang, H., Wang, G., Zhang, C., Su, R., Shi, X., Wang, X., 2020. Characterization of the development stages and roles of nutrients and other environmental factors in green tides in the southern Yellow Sea, China. Harmful Algae 98, 101893. https://doi.org/ 10.1016/j.hal.2020.101893.

Zheng, X., Gao, Z., Ning, J., Xu, F., Ai, J., 2017. Effects of different atmospheric correction methods on remote sensing monitoring results of Ulva prolifera. Environ. Scie. Technol. 40, 284-291. https://doi.org/10.3969/j.issn.1003-6504.2017.12.043 (In Chinese with English Abstract).

Zhou, M.-J., Liu, D.-Y., Anderson, D.M., Valiela, I., 2015. Introduction to the Special Issue on green tides in the Yellow Sea. Estuar. Coast. Shelf Sci. 163, 3-8. https://doi.org/ 10.1016/j.ecss.2015.06.023. 